\title{
Targeting Imbalance between IL-1 $\beta$ and IL-1 Receptor Antagonist Ameliorates Delayed Epithelium Wound Healing in Diabetic Mouse Corneas

\author{
Chenxi Yan, ${ }^{{ }^{\dagger}}$ Nan Gao, ${ }^{\dagger}$ Haijing Sun, ${ }^{\dagger}$ Jia Yin, ${ }^{\dagger}$ Patrick Lee, ${ }^{\dagger}$ Li Zhou, ${ }^{\ddagger}$ Xianqun Fan, ${ }^{*}$ and Fu-Shin Yu
}

From the Department of Ophthalmology, * Graduate Program, Shanghai Ninth Peoples' Hospital, Shanghai Jiao Tong University School of Medicine, Shanghai, China; the Department of Ophthalmology, Kresge Eye Institute, and the Department of Anatomy and Cell Biology, ${ }^{\dagger}$ Wayne State University School of Medicine, Detroit, Michigan; and the Department of Dermatology, ${ }^{\ddagger}$ Henry Ford Immunology Program, Henry Ford Health System, Detroit, Michigan

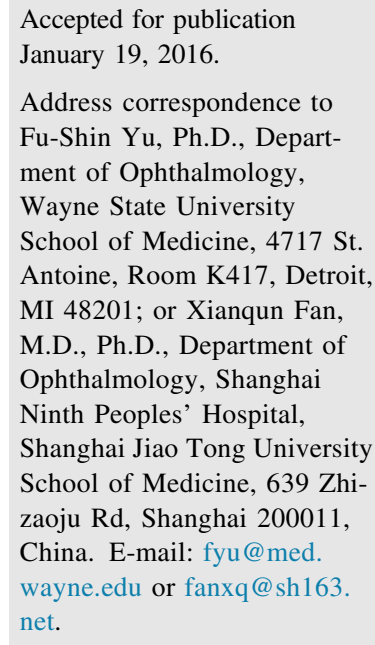

\begin{abstract}
Patients with diabetes mellitus often develop corneal complications and delayed wound healing. How diabetes might alter acute inflammatory responses to tissue injury, leading to delayed wound healing, remains mostly elusive. Using a streptozotocin-induced type I diabetes mellitus mice and corneal epithelium-debridement wound model, we discovered that although wounding induced marked expression of IL-1 $\beta$ and the secreted form of IL-1 receptor antagonist (sIL-1Ra), diabetes suppressed the expressions of sIL-1Ra but not IL-1 $\beta$ in healing epithelia and both in whole cornea. In normoglycemic mice, IL-1 $\beta$ or sIL-1Ra blockade delayed wound healing and influenced each other's expression. In diabetic mice, in addition to delayed reepithelization, diabetes weakened phosphatidylinositol 3-kinase-Akt signaling, caused cell apoptosis, diminished cell proliferation, suppressed neutrophil and natural killer cell infiltrations, and impaired sensory nerve reinnervation in healing mouse corneas. Local administration of recombinant IL-1Ra partially, but significantly, reversed these pathological changes in the diabetic corneas. CXCL10 was a downstream chemokine of IL-1 $\beta-I L-1 R a$, and exogenous CXCL10 alleviated delayed wound healing in the diabetic, but attenuated it in the normal corneas. In conclusion, the suppressed early innate/inflammatory responses instigated by the imbalance between IL-1 $\beta$ and IL-1Ra is an underlying cause for delayed wound healing in the diabetic corneas. Local application of IL-1Ra accelerates reepithelialization and may be used to treat chronic corneal and potential skin wounds of diabetic patients. (Am J Pathol 2016, 186: 1466-1480; http://dx.doi.org/10.1016/j.ajpath.2016.01.019)
\end{abstract}

With a rapid increase in the prevalence of diabetes mellitus (DM), ocular complications, including retinopathy and cataract, have become major causes of blindness in the world. Various types of corneal disorders are also relatively common in DM patients. ${ }^{1}$ Diabetic corneal complications, termed diabetic keratopathy, are resistant to conventional treatment regimens. ${ }^{2,3}$ Patients with diabetic keratopathy usually do not have detectable symptoms; however, once the cornea is injured, delayed epithelium-wound healing is often observed. ${ }^{4}$ Delayed epithelial wound closure may be associated with sight-threatening complications, such as stromal opacification, surface irregularity, and microbial keratitis. ${ }^{2}$ Like diabetic skin wounds, there is an unmet need for effective treatments of persistent wounds and ulceration in the DM cornea. Hence, a better understanding of the mechanisms underlying pathophysiology of delayed epithelium-wound healing in DM tissues is needed.

Chronic low-grade inflammation has been linked to the pathogenesis of diabetic complications. Moreover, DM patients experience simultaneous up-regulation and dysregulation of both innate and adaptive immunities; a chronically sustained low level of inflammation may blunt the sufficient

Supported by NIH/National Eye Institute (NEI) grants R01EY10869, EY17960 (F.-S.Y.), and p30 EY04078 (NEI core to Wayne State University; F.-S.Y.) and Research to Prevent Blindness unrestricted grant (to Kresge Eye Institute; F.-S.Y.).

Disclosures: None declared.

Portions of this work were presented at the Association for Research in Vision and Ophthalmology 2015 Annual Meeting held May 2-May 7, 2015, in Denver, CO. 
and timely reaction to injury and result in impaired damage control. ${ }^{5-8}$ Numerous studies have linked the overexpression of proinflammatory factors as an underlying cause of lowgrade inflammation. ${ }^{5,9,10}$ Among these factors, the IL-1 subfamily of cytokines, consisting IL-1 $\alpha$, IL- $1 \beta$, and IL-1 receptor antagonist (IL-1Ra, encoded by gene ILIRN in the humans), have attracted much attention because they have been implicated as a cause for the pathoencodesis of both type $1^{11,12}$ and type 2 diabetes ${ }^{13}$ and linked to complications with low-grade inflammation as a root cause. ${ }^{8,14}$ IL-1 type cytokines are major mediators of inflammatory and innate immune reactions, and blockade of IL- $1 \alpha$ and IL- $1 \beta$ by IL-1Ra has demonstrated a central role of IL-1 in several human autoinflammatory diseases, including rheumatoid arthritis and gout, and autoinflammatory syndromes. ${ }^{15,16}$ In the cornea, epithelial cell-produced IL-1 was suggested to act as a master regulator of corneal wound healing that modulates functions, such as the expression of matrix metalloproteinases and growth factor, and apoptosis of stromal keratocytes after injury. ${ }^{17,18}$ Interestingly, topical application of IL-1Ra was shown to inhibit inflammatory cell infiltration into the cornea, but its effect on epithelial wound closure was not reported. ${ }^{19}$ In the skin, IL-1Ra has been implicated in skin wound healing and fibrosis, with evidence of reduced skin fibrosis after application of anakinra, human recombinant IL-1Ra. ${ }^{20,21}$ The role(s) of IL-1 and IL-1Ra in reepithelialization, particularly their unbalanced production in DM tissues, remains elusive.

Corneal epithelium-debridement wounding is an ideal model to study reepithelialization and delayed wound healing. ${ }^{22}$ Using this model, we performed a genome-wide cDNA array analysis and observed that, although IL- $1 \alpha$ levels were not changed in response to wounding, the expression of IL- $\beta$ was greatly up-regulated in healing epithelia of both normal (NL) and DM corneas. Further analysis of cDNA array data revealed that wounding causes a moderate, but significant, increase (1.346-fold, $P=0.037)$ in NL, but a decrease $(-1.346$-fold, $P=0.024)$ of $I l 1 \mathrm{rn}$ in DM rat corneas, ${ }^{23}$ suggesting a diabetes-suppressed expression of IL-1Ra in response to wounding in the cornea. We postulated that this disturbed balance of IL-1 $\beta$ relative to IL-1Ra could be a determinant factor for delayed epithelium-wound closure observed in DM patients. Herein, we determined the expression patterns of IL-1 members in NL and DM corneas and their roles during diabetes-impaired epithelium-wound healing. Moreover, we evaluated the therapeutic potential of local application of anakinra to treat diabetic delayed wound healing and its underlying mechanisms.

\section{Materials and Methods}

\section{Animals and Induction of Diabetes}

All investigations conformed to the regulations of the Association for Research in Vision and Opthalmology Statement for the Use of Animals in Ophthalmic and Vision Research, the NIH. C57BL/6 mice were induced to develop type $1 \mathrm{DM}$ according to a low-dose streptozotocin induction protocol. Animals with blood glucose levels $>350 \mathrm{mg} / \mathrm{dL}$ were considered DM and were used for experiments, with age-matched, NL animals as the control, at 10 weeks after streptozotocin injection. ${ }^{24}$

\section{Corneal Epithelial Debridement Wound Model and Tissue Collection}

Mouse corneal epithelium-debridement wounds were made as described. ${ }^{24}$ Anesthetized mice were first demarcated with a trephine in the central cornea $(1.5 \mathrm{~mm})$, and corneal epithelial cells (CECs) were removed under a dissecting microscope. CECs were collected by quiescent CEC debridement and by scraping CECs that migrated into wound beds at 20 hours after wounding (hpw). Whole corneas were dissected along with the limbal region.

\section{RNA Extraction and PCR Analysis}

RNA was extracted from the collected CECs or dissected whole corneas using an RNeasy Mini Kit (Qiagen, Valencia, CA). cDNA was generated with an oligo (dT) primer, followed by analysis using RT-PCR or real-time quantitative PCR (qPCR) with SYBR Green (StepOnePlus; Applied Biosystems, Carlsbad, CA), with $\beta$-actin expression as an internal control. qPCR results were first normalized with the levels of $\beta$-actin and then compared with the levels of NL (value, 1), presented as fold changes.

\section{Subconjunctival Injection of siRNAs, Neutralizing Antibody, and Proteins}

Subconjunctival injection is a routine procedure used in the ophthalmology clinic to treat ocular diseases because it allows injected materials to slowly diffuse into the cornea. The subconjunctival injection volume for mice was $5 \mu \mathrm{L}$ per injection. Anesthetized mice were injected with $1 \mu \mathrm{g}$ per cornea anti-IL$1 \beta$ or IgG as the control (R\&D Systems, Minneapolis, MN); proteins [anakinra, $125 \mathrm{ng}$ per cornea (SOBI, Waltham, MA); CXCL10, 250 ng per cornea (PeproTech, Rocky Hill, NJ)] with phosphate-buffered saline containing $0.1 \%$ bovine serum albumin as the control were injected 4 hours before wounding. ON-TARGETplus mouse IL-1RA and ON-TARGETplus nontargeting pool siRNAs were purchased from Dharmacon (Pittsburgh, PA); $20 \mu \mathrm{mol} / \mathrm{L}$ solutions of siRNA were injected twice ( 24 and 4 hours) before wounding.

\section{Immunohistochemistry and in Situ Cellular Apoptosis Assay of Mouse Corneas}

Mouse eyes were enucleated, embedded in Tissue-Tek OCT compound (Miles Inc., Elkhart, IN), frozen on dry ice, divided into sections (6 $\mu \mathrm{m}$ thick), and mounted to polylysine-coated glass slides (Polysciences Inc., Warrington, PA). After fixation with $4 \%$ paraformaldehyde, the 
cryostat sections of corneas were incubated with rabbit primary antibody Ki-67 (Abcam) or CXCL10 (PeproTech) as described. ${ }^{24}$ In situ apoptotic cells were detected using apoptosis-detection kit [ApopTag plus terminal deoxynucleotidyl transferase-mediated dUTP nick-end labeling (TUNEL) staining; Chemicon, Temecula, CA]. Corneal cryostat sections were fixed and incubated with TUNEL reagents, following the manufacturer's direction. The negative controls for TUNEL staining include normal cornea section TUNEL staining, and DM healing cornea section TUNEL staining with omitted terminal deoxynucleotidyl transferase. Images were taken under confocal microscope (SP8; Leica, Wetzlar, Germany) or under a Carl Zeiss fluorescence microscope Axioplan 2 equipped with an ApoTome digital (Carl Zeiss, Thornwood, NY).
Protein Extraction, ELISA, Western Blot Analysis, and Protein Array

CECs or whole corneas were collected and homogenized in radioimmunoprecipitation assay buffer. Protein concentration was determined by protein assay kit (Thermo, Waltham, MA). Enzyme-linked immunosorbent assay (ELISA; mouse IL-1 $\beta$, IL-1Ra, and CXCL10) and protein array were performed following manufacturer's protocols (R\&D Systems). For the protein array assay, each membrane was probed with $200 \mu \mathrm{g}$ corneal proteins (extracted from five corneas). Western blot analysis with Phospho-Akt and Akt antibodies (Cell Signaling Technology, Danvers, MA) was performed as described. ${ }^{25}$ Membranes were imaged for different exposure times using Kodak Imaging Station 4000R Pro (Rochester, NY).
A
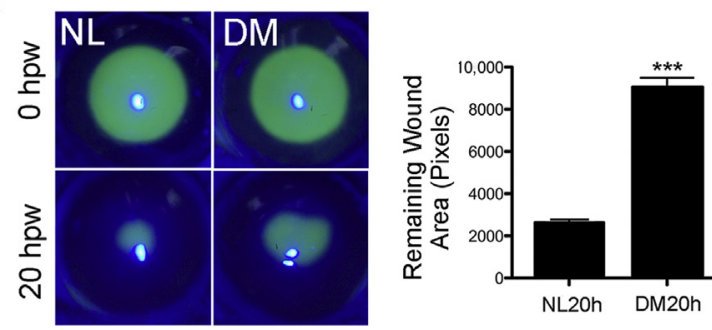

C

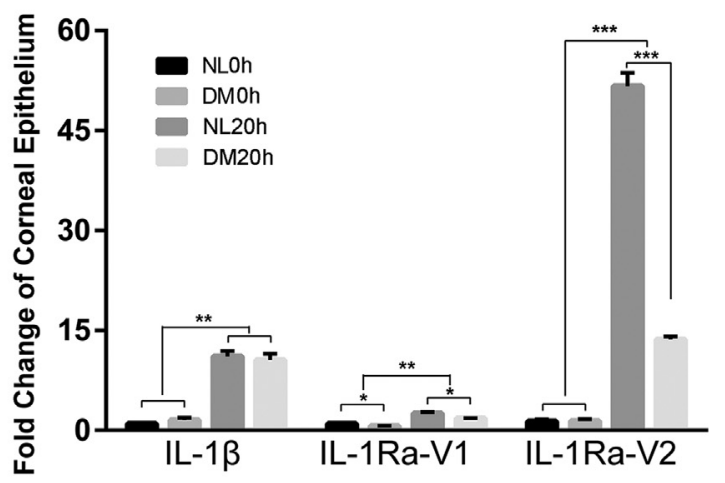

E

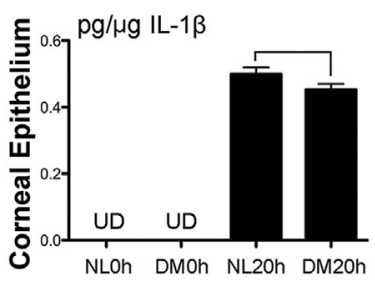

$\mathbf{F}$

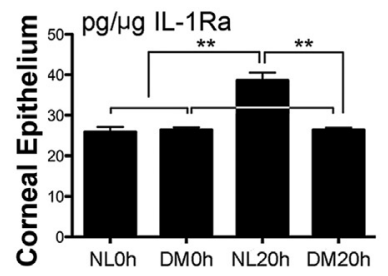

B

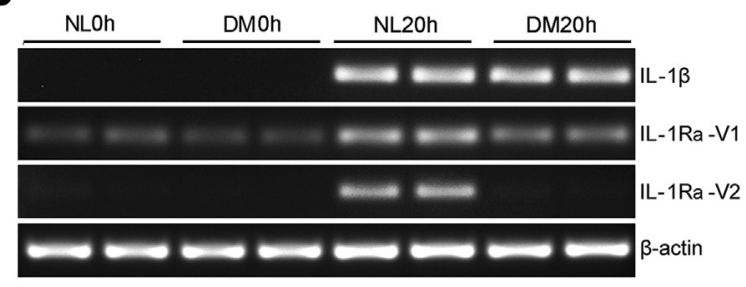

D

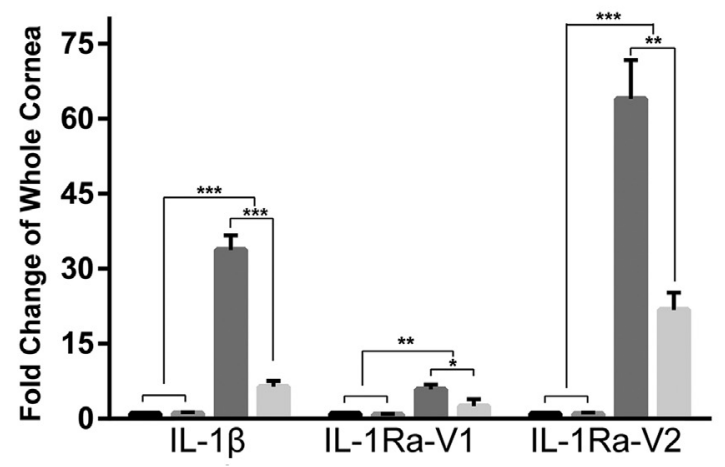

G

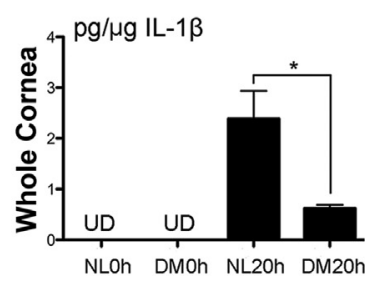

H

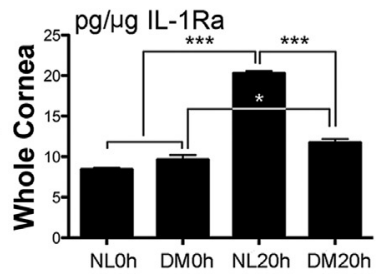

Figure 1 Differential expression of IL-1 family cytokines in delayed diabetic corneal wound healing. Streptozotocin (STZ)-induced diabetes mellitus (DM) and age-matched normal (NL) mice were wounded by epithelium-debridement (1.5-mm diameter). Conditions were as such, NL and DM unwound samples, NL and DM healing samples at 20 hours after wounding (hpw). Samples were subjected to RNA isolation and protein extraction. A: The original and remaining wounds at 20 hpw visualized by fluorescein staining under slit lamp. Analysis of fluorescent-stained areas (Adobe Photoshop software version CS6; Adobe, San Jose, CA). Column was presented as average pixels of remaining wound areas of each group (unpaired $t$-test). B: Regular PCR analysis of IL- $1 \beta$ and IL-1 receptor antagonist (IL-1Ra)-V1 and IL-1Ra-V2 in corneal epithelia. C and D: Real-time quantitative PCR analysis of IL-1 $\beta$ and IL-1Ra-V1 and IL-1Ra-V2 in corneal epithelia and whole corneas. Enzyme-linked immunosorbent assay of IL-1 $\beta$ (E) and IL-1Ra (F) in corneal epithelia and IL-1 $\beta(\mathbf{G})$ and IL-1Ra $(\mathbf{H})$ in whole corneas. Comparison of IL-1 $\beta$ were made between two conditions, NL 20 and DM 20 (unpaired $t$-test). Comparison of IL-1Ra were made among four conditions (one-way analysis of variance). Two independent experiments were performed. Data are given as means \pm SEM $(\mathbf{A}$ and $\mathbf{C}-\mathbf{H}) . n=5(\mathbf{A}) ; n=3(\mathbf{C}-\mathbf{H}) .{ }^{*} P<0.05,{ }^{* *} P<0.01$, and ${ }^{* * *} P<0.001$. UD, undectable. 


\section{Whole Mount Confocal Microscopy}

Enucleated mouse eyes from euthanized animals were processed, and whole corneas were stained for whole mount confocal microscopy, as described in our early studies. ${ }^{26}$ For staining of neutrophils or natural killer (NK) cells, fluorescein isothiocyanate conjugated antibodies $(5 \mu \mathrm{g} / \mathrm{mL})$ of NIMP-R14 (Hycult Biotech, Plymouth Meeting, PA) or NK1.1 (eBioscience, San Diego, CA) were incubated with the cornea, respectively. For nerve staining, an additional 2-day permeabilization was performed before incubation with TUJ1 antibody $\left(2 \mu \mathrm{g} / \mathrm{mL}\right.$; Covance Research, Princeton, NJ). ${ }^{27}$ The stained tissues were coverslipped with mounting medium (H1000; Vector Laboratories, Burlingame, CA) and examined under a confocal microscope (SP8; Leica). Images were analyzed by ImageJ version $1.48 \mathrm{v}$ (NIH, Bethesda, MD). To quantitate cell numbers, images were analyzed by threshold-based automatic particle counting. ${ }^{28}$ To calculate the percentile of nerve coverage in each cornea, images were adjusted with a threshold, analyzed as particle (show mask), then analyzed by percentage area.

\section{Statistical Analysis}

Data were presented as means \pm SD. Statistical differences among three or more groups were first identified using oneway analysis of variance, followed by $t$-test for pair-wise comparison. The error bars represent SEM; differences were considered statistically significant at $P<0.05$.

\section{Results}

\section{Delayed Epithelium-Wound Healing and Differential Expression of IL-1 Family Cytokines in Diabetic Corneas}

Our cDNA array data showed that IL- $1 \alpha$ levels are not significantly changed and IL- $1 \beta$ levels are increased greatly in healing rat CECs, whereas the levels of IL-1Ra are increased moderately and significantly $(1.35, P=0.034)$ in NL, but decreased $(-1.39, P=0.021)$ in DM rat corneas, giving 1.71fold decrease $(P=0.0017)$ in DM healing CECs compared with the normal CECs. ${ }^{23}$ Using a streptozotocin mouse model, which showed delayed epithelium-wound closure (Figure 1A), we surveyed the expression of IL-1 $\beta$ and IL-1Ra in the mouse corneas. There are three alternatively spliced Il1rn
mRNAs with variant 3 (V3) untranslated ${ }^{29}$; we, therefore, designed primers to amplify IL-1Ra-V1 (encoding intracellular, icIL1Ra) and IL-1Ra-V2 (encoding secreted, sIL1Ra) (Table 1). In unwounded corneas, although IL-1Ra-V1 was constitutively expressed in NL and DM CECs, IL-1 $\beta$ and IL-1Ra-V2 were undetectable by RT-PCR up to 30 cycles of amplification (Figure 1B); however, a visible band was seen when 35 cycles of amplification were performed for both genes (data not shown).

Wounding induced IL-1 $\beta$ and IL-1Ra-V2 expression and enhanced IL-1Ra-V1 expression at the mRNA levels, whereas diabetes down-regulated the wound-induced expression of IL-1Ra-V2 and to a lesser extent IL-1Ra-V1, but not IL-1 $\beta$. Using relative qPCR, we found that wounding induced 11.14-, $2.60-$, and 51.66-fold increases of IL-1 $\beta$, IL-1Ra-V1, and IL-1Ra-V2, respectively, in normal CECs, and diabetes suppressed the wound-induced expression of IL-1Ra-V1 by $30 \%$ and IL-1Ra-V2 by 3.78-fold, respectively, without affecting IL-1 $\beta$ expression (Figure $1 \mathrm{C}$ ). In the whole corneas, similar expression patterns were observed for IL-1Ra-V1 and IL-1RaV2. On the other hand, the levels of $111 \mathrm{~b}$ were markedly higher in wounded cornea of NL mice (33.77-fold increase); the wound-induced expressions were greatly suppressed by diabetes (declined to 6.345-fold increase over the control) (Figure 1D).

At the protein levels, IL-1 $\beta$ concentrations in unwounded CECs were lower than the detectable range of the ELISA kit, and were approximately $0.5 \mathrm{pg} / \mu \mathrm{g}$ of healing CECs of both NL and DM corneas (Figure 1E). Unlike IL- $1 \beta$, relatively high levels of IL-1Ra, presumably icIL-1Ra because of low levels of IL-1Ra-V2 mRNA, were detected in unwounded CECs of both normal and diabetic corneas; a significant increase in the IL-1Ra concentration was observed in the healing CECs of the NL, but not DM corneas (Figure $1 \mathrm{~F}$ ). In the whole cornea, much higher levels of IL-1 $\beta(2.1 \mathrm{pg} / \mu \mathrm{g})$ were detected in healing corneas than that in CEC extract. Remarkably, the level of IL-1 $\beta$ in the healing corneas of NL was markedly higher than that of DM mice (Figure 1G); this great increase in NL, but not DM, healing corneas may be related to the infiltration of large amounts of Il1 $\beta$-expressing cells in $18 \mathrm{hpw}$ NL, but not DM corneas (Supplemental Figure S1). Moreover, the overall levels of IL-1Ra in unwounded corneas were lower than that in CECs of both $\mathrm{NL}$ and DM mice. Wounding markedly elevated the levels

Table 1 Primers for PCR

\begin{tabular}{lll}
\hline Primer name & Forward primer & Reverse primer \\
\hline$\beta$-Actin & $5^{\prime}$-AGCCATGTACGTAGCCATCC-3' & $5^{\prime}$-CTCTCAGCTGTGGTGGTGAA-3' \\
IL-1 $\beta$ & $5^{\prime}$-GGAGAAGCTGTGGACGCTA-3' & $5^{\prime}$-GCTGATGTACCAGTTGGGGA-3' \\
IL-1Ra-V1 & $5^{\prime}$-CTGGAGTGAGACGTTGGAAGG-3' & $5^{\prime}$-CATCTTGCAGGGTCTTTTCCC-3' \\
IL-1Ra-V2 & $5^{\prime}$-GGGACCCTACAGTCACCTAA-3' & $5^{\prime}-$ GGTCCTTGTAAGTACCCAGCA-3' \\
Cxcl5 & $5^{\prime}$-TGCCCTACGGTGGAAGTCAT-3' & $5^{\prime}-$ AGCTTTCTTTTTGTCACTGCCC-3' \\
Ccl5 & $5^{\prime}$-TGCTCCAATCTTGCAGTCGT-3' & $5^{\prime}-$ TCTTCTCTGGGTTGGCACAC-3' \\
Cxcl10 & $5^{\prime}$-CCATCAGCACCATGAACCCAAGT-3' & $5^{\prime}$-CACTCCAGTTAAGGAGC-3' \\
\hline
\end{tabular}

$\mathrm{Ccl}$, chemokine ligand; IL-1Ra, IL-1 receptor antagonist. 
A

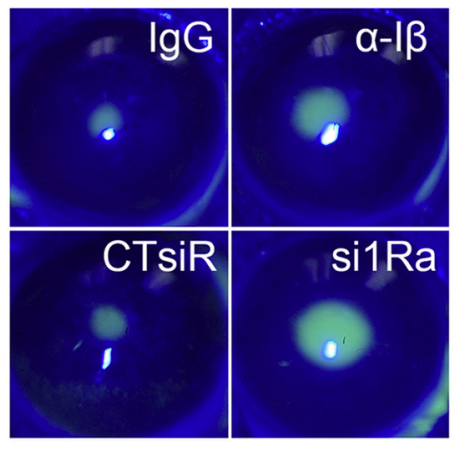

D

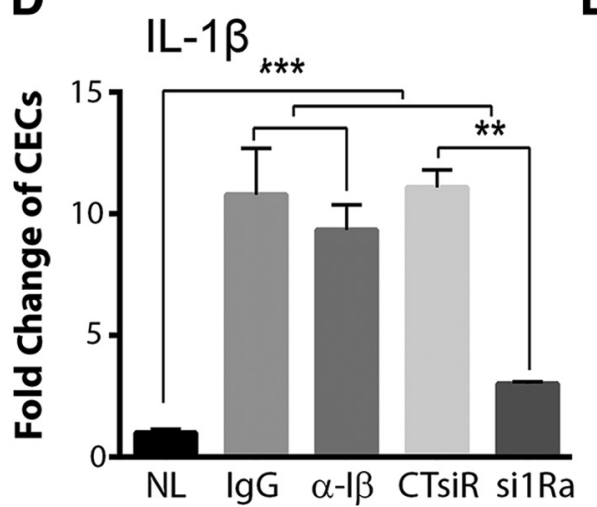

B

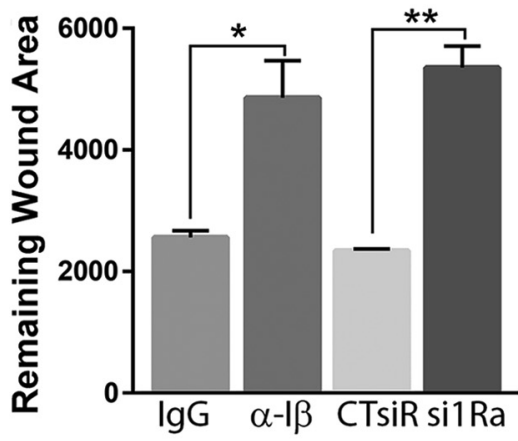

$\mathbf{E}$

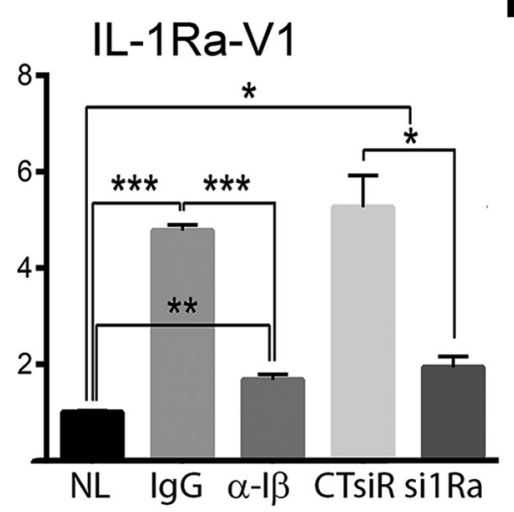

C

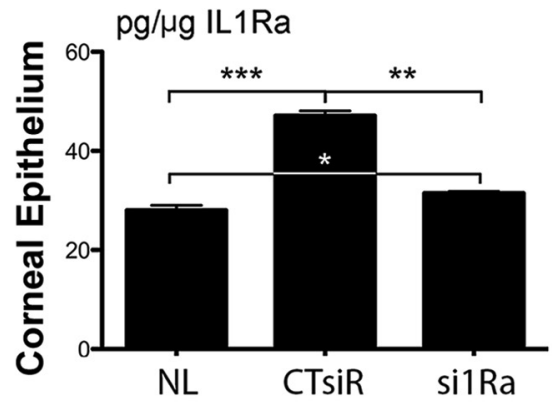

$\mathbf{F}$

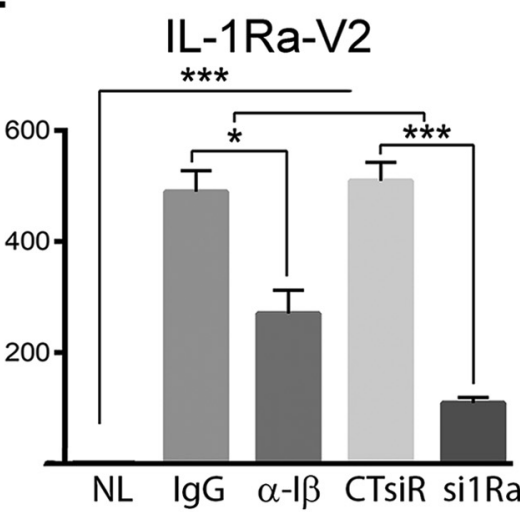

Figure 2 Altering IL-1 signaling in normal healing cornea affects corneal epithelial wound healing rate and gene expression in corneal epithelial cells. A: Normal (NL) mice were subconjunctivally injected with $5 \mu \mathrm{L} \mathrm{IgG}(200 \mathrm{ng} / \mu \mathrm{L})$, left eyes, and IL-1 $\beta$ neutralizing antibody $(200 \mathrm{ng} / \mu \mathrm{L})$, right eyes, once at -4 hours, or injected with non-specific control siRNA $(20 \mu \mathrm{mol} / \mathrm{L})$, left eyes, and IL-1 receptor antagonist (IL-1Ra)-specific siRNA $(20 \mu \mathrm{mol} / \mathrm{L})$, right eyes, twice at -24 and then -4 hours. Epithelial samples for each condition were collected. Representative images of wounds at 20 hours after wounding (hpw). B: Remaining wounds were calculated and analyzed with paired $t$-test. C: Enzyme-linked immunosorbent assay confirmation of siRNA knockdown of IL-1Ra (all isoforms) on the protein level, analyzed with one-way analysis of variance. Expressions of IL-1 $\beta$ (D), IL-1Ra-V1 (E), and IL-1Ra-V2 (F) in naïve (NL), IgG control (IgG), mouse IL-1 $\beta$ neutralizing antibody $(\alpha-I \beta)$ treated, control, non-specific siRNA (CTsiR), and IL-1Ra siRNA (si1Ra) treated corneal epithelial cells (CECS) assessed by real-time quantitative PCR and analyzed with one-way analysis of variance. Data are given as means \pm SEM (B and $\mathbf{D}-\mathbf{F}) . n=5$ (B); $n=3$ (D-F). ${ }^{*} P<0.05,{ }^{*} P<0.01$, and ${ }^{* * *} P<0.001$.

of IL-1Ra in NL and slightly in DM corneas (Figure 1H). Although the total levels of IL-1Ra increased $50 \%$ in epithelial cells and approximately onefold in the whole corneas, the levels of sIL-1Ra transcribed from IL1-Ra-V2 mRNA could be greatly elevated in NL, but not DM, healing corneas. This difference in IL1-Ra-V2 mRNA transcription between NL and DM healing corneas resulted in an increase in the ratio of IL- $1 \beta$ versus sIL-1Ra in the extracellular milieu of DM corneal epithelia.

\section{Role of IL-1 Signaling in Regulating Corneal Epithelium-Wound Healing in Normal Mice}

To test the hypothesis that early and robust induction of IL-1 $\beta$ is required for initiating proper response to wounding in NL corneas, IL- $1 \beta$ neutralizing antibody was subconjunctivally injected before epithelium-debridement. Compared with the controls, the presence of IL-1 $\beta$ neutralizing antibody significantly delayed corneal epithelium-wound closure
(Figure 2, A and B). We then performed siRNA knockdown of IL-1Ra via subconjunctival injection ${ }^{30}$ in NL mice. IL-1Ra knockdown resulted in much-delayed wound healing compared with control siRNA-treated mice. Figure $2 \mathrm{C}$ shows successful down-regulation of wound-induced expression of IL-1Ra protein.

Using qPCR, we assessed the expression of IL-1 $\beta$ and IL-1Ra under these four conditions with NL corneas as the control. Although IL-1 $\beta$ blockade had no effects on wound-induced IL-1 $\beta$ expression (Figure 2D), IL-1Ra knockdown resulted in a significant decrease in $\mathrm{IL}-1 \beta$ expression (Figure 2, E and F). As for IL-1Ra-V1, wounding-induced expression (approximately fivefold) was suppressed by the down-regulation of IL-1 $\beta$ or IL$1 \mathrm{Ra}$. Epithelium wounding induced robust expression of IL-1Ra-V2, which was moderately inhibited by IL-1 $\beta$ neutralization and markedly, as expected from the effects of siRNA, by IL-1Ra siRNA at the mRNA levels (Figure 2F). 

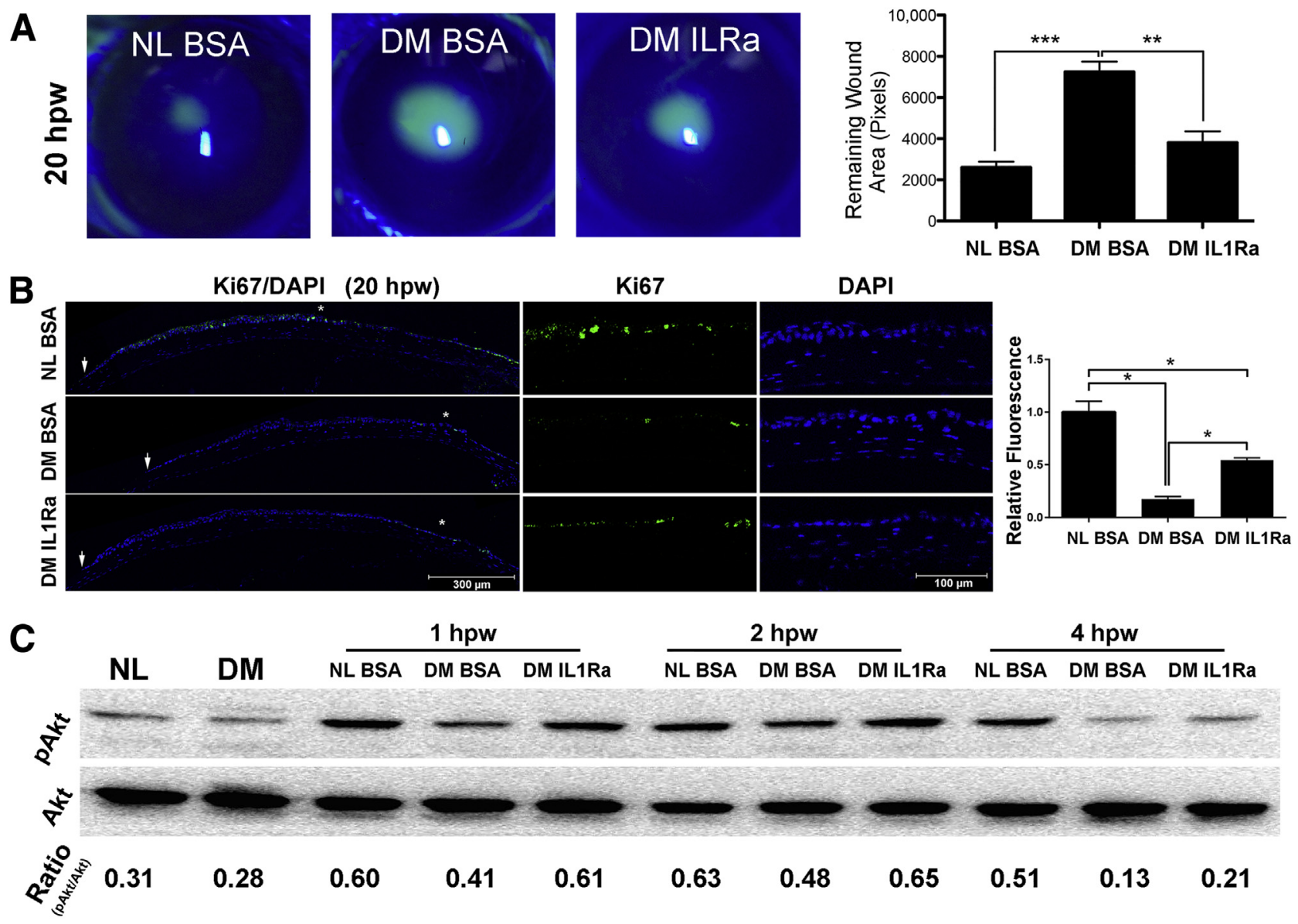

Figure 3 Effects of exogenous IL-1 receptor antagonist (IL-1Ra) on diabetic epithelial wound healing rate, proliferation, and phosphatidylinositol 3-kinase (PI3K)-Akt activation. A: Normal (NL) mice were injected subconjunctivally with $5 \mu$ L phosphate-buffered saline (PBS) containing $0.1 \%$ bovine serum albumin (BSA), diabetes mellitus (DM) mice were subconjunctivally injected with $5 \mu \mathrm{L}$ PBS containing $0.1 \% \mathrm{BSA}$, left eyes, or IL-1Ra ( $25 \mathrm{ng} / \mu \mathrm{L}$, diluted from anakinra injection solution), right eyes, 4 hours before epithelium debridement. Corneas were imaged at 20 hours after wounding (hpw), and the wound sizes were calculated and results were presented as the mean of the remaining wound area. B: Proliferation assay via immunofluorescence staining for Ki-67. Staining was quantitated by calculating the area covered with green in each image (showing cornea from limbal region to epithelial leading edge) using ImageJ version $1.48 \mathrm{v}$. The result was presented as relative fluorescence with the value derived from NL healing corneal sections as 1 . Arrows indicate the leading edge of healing epithelium. Areas marked with asterisks are shown at higher magnification to the right. Two independent experiments were performed. C: Western blot analysis of phospho-Akt (pAkt) with Akt as the internal control. The intensity of each band was digitized by ImageJ, and ratio of pAkt/Akt was calculated and presented. Data are given as means $\pm \operatorname{SEM}(\mathbf{A}$ and $\mathbf{B}) . n=5(\mathbf{A}) ; n=3(\mathbf{B}) .{ }^{*} P<0.05,{ }^{*} P<0.01$, and ${ }^{*} * * P 0.001$ (one-way analysis of variance).

\section{Exogenous IL-1Ra Accelerates Wound Healing and Restores the Wound Response in Diabetic Corneas}

To determine whether replenishing IL-1Ra improves wound responses in the DM corneas, we applied $125 \mathrm{ng}$ anakinra in $5 \mu \mathrm{L}$ to each cornea subconjunctivally and observed significantly accelerated wound closure in the DM (Figure 3A), but not NL corneas (Supplemental Figure S2).

To assess cell proliferation (Figure 3B), Ki-67 immunostaining was performed, and positive cells were seen in the stratified healing epithelium and abundantly in the limbal region of NL cornea. In the diabetic untreated cornea, only few Ki-67-positive cells were seen in a region near the limbus. In the diabetic IL-1Ra-treated cornea, $\mathrm{Ki}-67-$ positive cells were more numerous than in the diabetic untreated cornea, and were fewer than in the NL cornea.
The phosphatidylinositol 3-kinase (PI3K)-Akt pathway is known to regulate cell survival and is defective in diabetic corneas. ${ }^{25}$ Western blot analysis (Figure 3C) revealed that at 1 and $2 \mathrm{hpw}$, wounding increased phosphorylated-Akt in the NL and to a lesser extent in the DM cornea, the presence of IL-1Ra restored the intensity of phosphorylated-Akt to a level similar to the NL corneas. However, at $4 \mathrm{hpw}$, phosphorylated-Akt remained high in NL corneas, whereas it substantially declined to the basal levels in DM corneas with or without IL-1Ra treatment.

We previously observed TUNEL-positive cells in stationary and healing epithelia of DM, but not nondiabetic, rat and human corneas. ${ }^{25}$ To assess the effects of sIL-1Ra on the reverse of cell apoptosis in diabetic corneas, we performed TUNEL staining (Figure 4A). Two negative controls, consisting of TUNEL-stained normal unwounded corneal sections, and wounded DM corneal sections TUNEL-stained 


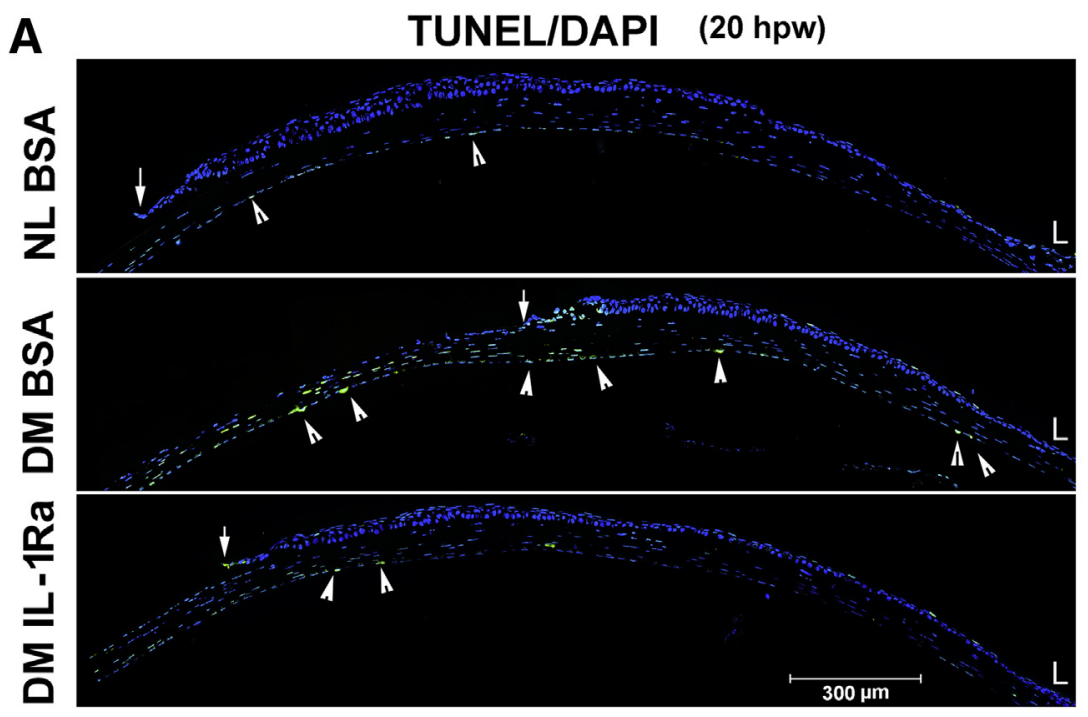

D

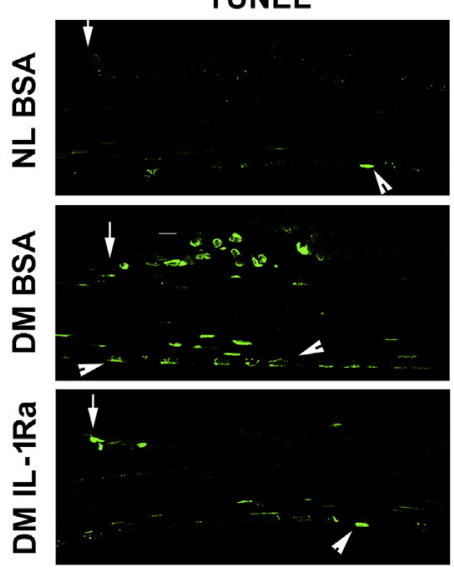

DAPI
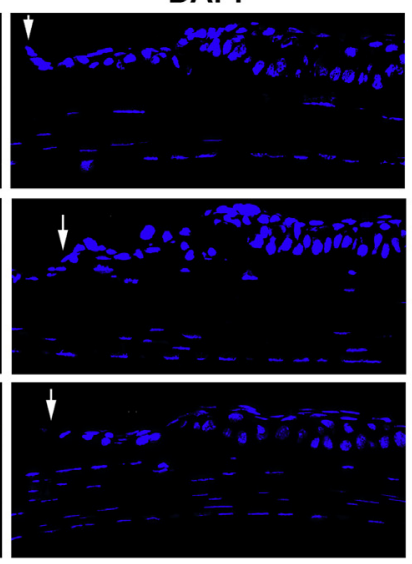

B

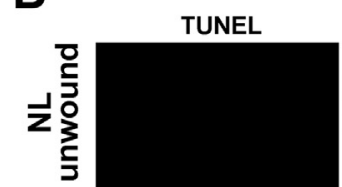

Without TUNEL

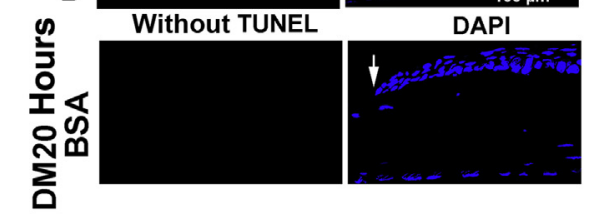

C

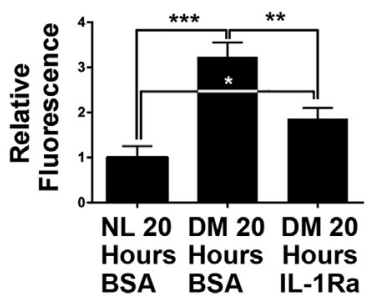

DAPI

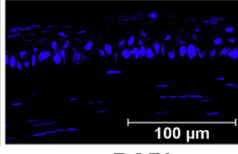

BSA BSA IL-1Ra
TUNEL
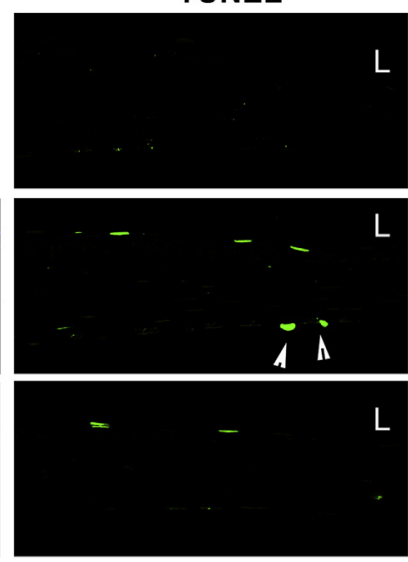

DAPI

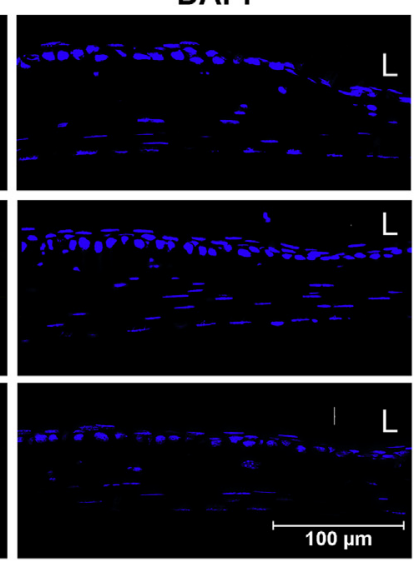

Figure 4 Effects of exogenous IL-1 receptor antagonist (IL-1Ra) on apoptosis of diabetic corneas. Cell apoptosis in healing corneas was assessed using in situ terminal deoxynucleotidyl transferase-mediated dUTP nick-end labeling (TUNEL) staining with DAPI counterstaining. A: Low magnification showing from limbal region (L) to the leading edge (arrows). B: Negative controls: Normal cornea section stained with TUNEL staining and healing diabetes mellitus (DM) cornea stained with TUNEL staining omits terminal deoxynucleotidyl transferase with DAPI counterstaining. C: Staining was quantitated by calculating the area covered with green in each image using ImageJ version $1.48 \mathrm{v}$. The result was presented as relative fluorescence with the value derived from normal (NL) healing corneal sections as 1. D: Amplified images of the leading edges (arrows) and limbal regions (L) shown in A. Arrows indicate the leading edge of healing epithelium; arrowheads, TUNEL-positive endothelial cells (A and D). Data are given as means \pm SEM (C). $n=5(\mathbf{C}) .{ }^{*} P<0.05,{ }^{* *} P<0.01$, and ${ }^{* * *} P$ $<0.001$ (one-way analysis of variance). Original magnification, $\times 20$ (D). BSA, bovine serum albumin.

without terminal deoxynucleotidyl transferase in the labeling mix, had no detectable fluorescence (Figure 4B). Analysis of the area covered with fluorescence in the entire region revealed significant increases in the amount of fluorescent staining between normal and diabetic corneas and its marked reversal by IL-1Ra treatment in the diabetic corneas (Figure 4, $A$ and C). There were no TUNEL-positive CECs from the limbus to the leading edge in healing epithelium of the NL cornea (NL bovine serum albumin); there were, however, a few infiltrated cells in the stroma and several of what appeared to be endothelial cells that were TUNEL positive (Figure 4, $\mathrm{A}$ and D). In DM corneas (DM bovine serum albumin), numerous TUNEL-positive epithelial and stromal-infiltrating cells were detected around the leading edge and in the denuded stroma. IL-1Ra (DM IL-1Ra) greatly reduced, but not entirely eliminated, TUNEL-positive cells in the migratory epithelial sheet and in the stroma near the leading edge of the DM corneas (Figure 4A). The differences in the number of TUNEL-positive cells among NL, DM untreated, and DM treated corneas were apparent, with high-magnification images showing the leading edges and the limbal regions (Figure 4D).

Unexpectedly, there were two in normal, two in IL-1Ratreated, and many TUNEL-positive endothelial cells in diabetic, untreated corneal sections (Figure 4, A and D). The fact that these TUNEL-positive cells morphologically differed from other endothelial cells (thicker, but shorter) in NL and IL$1 \mathrm{Ra}-$ treated DM corneas, and that the TUNEL staining did not exactly match with DAPI staining of the nuclei in the diabetic 

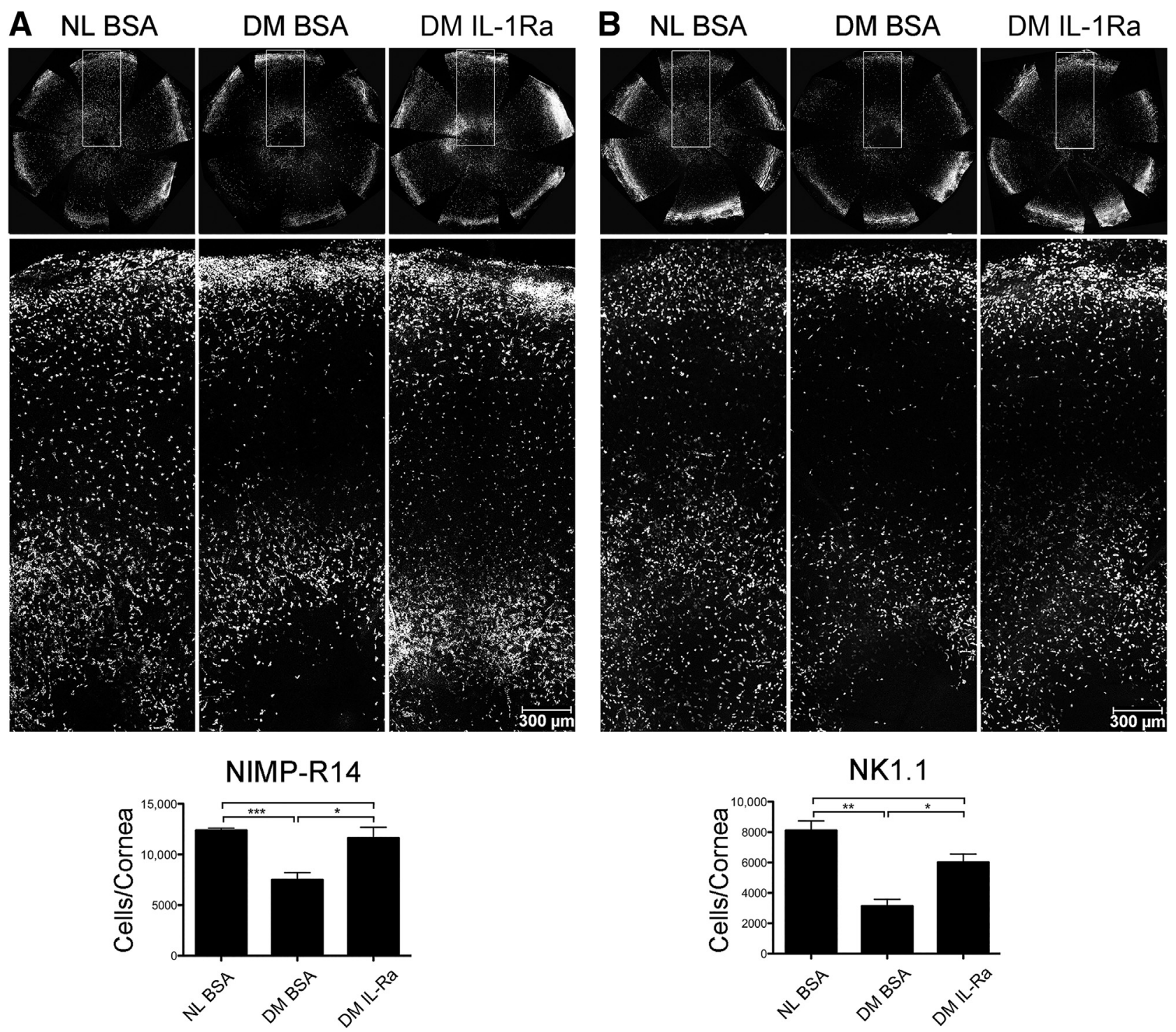

Figure 5 Effects of exogenous IL-1 receptor antagonist (IL-1Ra) on the infiltration of neutrophils and natural killer (NK) cells in diabetic healing corneas. A: Infiltrating neutrophils stained by NIMP-R14. B: Infiltrating NK (T) cells stained by NK1.1. Corneas were whole mount stained and imaged under a confocal microscope using Stage Scanning Program (SP8; Leica). Representative whole cornea images for each condition (top panels), high-magnification images for areas denoted by boxed areas (middle panels), and the cell number analysis resulted from cells per particle calculation of whole cornea images excluding outer one fifth (densely packed area representing the limbal region) (bottom panels) by ImageJ version $1.48 \mathrm{v}$. The results were presented as the average numbers of NIMP-R14 or NK1.1 positive cells per particle per cornea. Two independent experiments were performed. Data are given as means \pm SEM. $n=3$ (A and B). ${ }^{*} P<0.05,{ }^{* *} P<0.01$, and ${ }^{* *} P<0.001$ (one-way analysis of variance). BSA, bovine serum albumin; DM, diabetes mellitus; NL, normal.

untreated corneas suggests potential false-positive staining of some endothelial cells in injured mouse corneas.

Effects of IL-1Ra on the Infiltration of Neutrophils and NK Cells

Neutrophils ${ }^{31}$ and NK cells ${ }^{32}$ have been shown to play a role in corneal epithelium-wound healing, stromal remolding, and nerve regeneration. We next investigated whether their infiltrations were altered in DM healing corneas and the effects of IL-1Ra herein. Whole mount confocal microscopy revealed that at the leading edge, there were large amounts of NIMP-R14-positive cells in NL corneas, whereas significantly less in DM corneas. Presence of IL-1Ra resulted in a marked increase in the infiltration in neutrophils, particularly near the leading edge (Figure 5A). Similar patterns of infiltration and distribution of NK1.1positive cells were also observed (Figure 5B).

\section{Role of IL-1Ra in Corneal Innervation and Nerve Regeneration after Wounding}

We previously observed a reduced corneal sensitivity and innervation, and more important delayed reinnervation, after epithelial injury in DM animals. ${ }^{26,27}$ Herein, we determined the role of IL-1Ra in corneal sensory nerve regeneration 

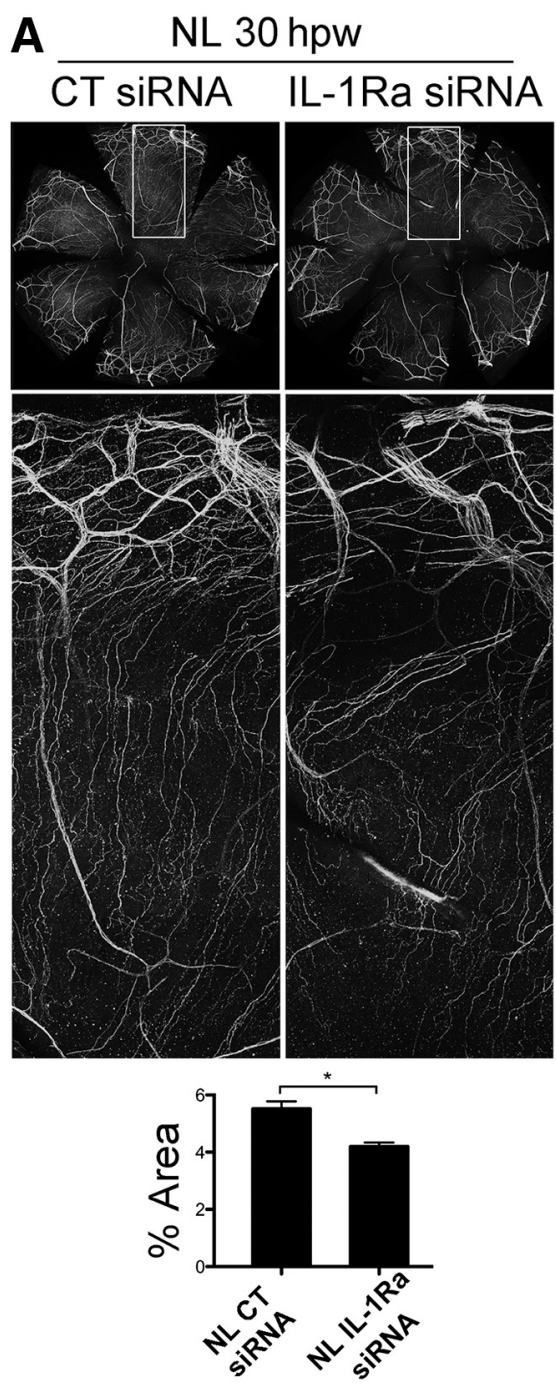

B
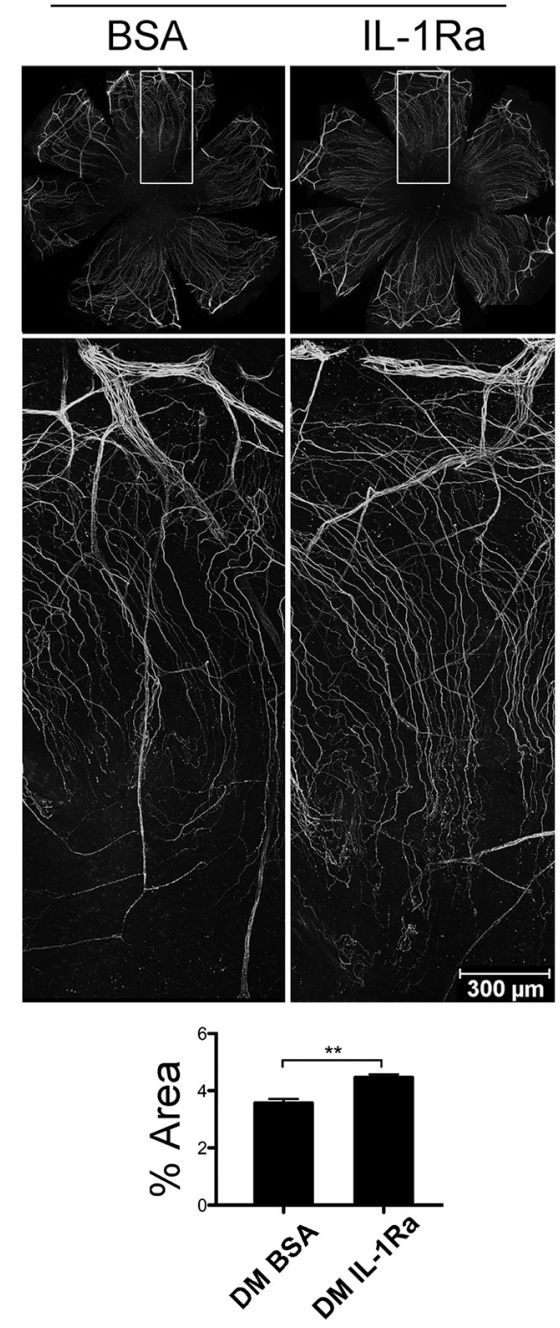

Figure 6 Effects of IL-1 receptor antagonist (IL-1Ra) on corneal nerve regeneration in healing corneas. A: Normal (NL) corneas pretreated with control, left eyes, and IL-1Ra siRNA, right eyes. B: Diabetes mellitus (DM) corneas pretreated with phosphate-buffered saline (PBS) containing $0.1 \%$ bovine serum albumin (BSA), left eyes, and IL-1Ra recombinant protein, right eyes. Whole corneas of each condition were collected at indicated time points and whole mount stained for $\beta$-tubulin 3 . Whole cornea images for each condition (top panels), high-magnification images for areas denoted by boxed areas (middle panels), and analysis of percentile of nerve coverage (bottom panels). The areas of cornea covered with staining were measured using ImageJ version $1.48 \mathrm{v}$ and presented as mean of percentage covered. Two independent experiments were performed. Data are given as means \pm SEM. $n=3(\mathbf{A}$ and $\mathbf{B})$. ${ }^{*} P<0.05,{ }^{* *} P<0.01$ (paired $t$-test). CT, control; hpw, hours after wounding. using the total area covered by the nerve staining as the parameter. In NL corneas, IL-1Ra siRNA significantly reduced corneal innervation in the post-wounded cornea (Figure 6A). For DM corneas, exogenous IL-1Ra significantly enhanced nerve regeneration (Figure 6B). The effects of IL-1Ra knockdown in the NL cornea were the lack of sensory nerve ending sprouting near the limbal region and the disorientation of nerve endings. In the DM cornea, presence of exogenous IL-1Ra mostly increased the density of nerve endings and the length of the newly formed nerve ending; the latter, however, may be related to the increased rate of epithelial wound closure.

\section{Effects of IL-1Ra on the Expression of Cytokines and Chemokines}

Given the essential role of IL-1 signaling in inflammation and the chronic low-grade inflammatory nature of diabetes, we next determined the effects of IL-1Ra on the expression of cytokines in response to epithelial wounding, and we assessed the expressions of 111 cytokines, chemokines, and growth factors using a Proteome Profiler Mouse XL Cytokine Array Kit (R\&D Systems). Among the 111 genes, Cxcl10, Cxcl5, and $\mathrm{C} c \mathrm{~S} 5$ exhibited a wound-induced and diabetes-suppressed expression in the healing corneas. IL-1Ra partially restored the diabetes-suppressed expressions of these three genes at the protein level (Figure 7A). To confirm the cytokine array results, qPCR with unwounded NL and DM corneas as the controls was performed. Although no differences were observed in unwounded NL and DM CECs, the expressions of CXCL10, CXCl5, and chemokine ligand (CCL) 5 were elevated to different extents, and these elevations were suppressed by diabetes but restored by the IL-1Ra treatment in the diabetic corneas (Figure 7B).

Differential Roles of CXCL10, an IL-1 $\beta-I L-1 R a-$ Mediated Chemokine, in Corneal Epithelial Wound Healing of the Normal and Diabetic Mouse Corneas

Figure 7C shows the verification of CXCL10 expression pattern using ELISA with mouse CEC extracts. In NL 
A
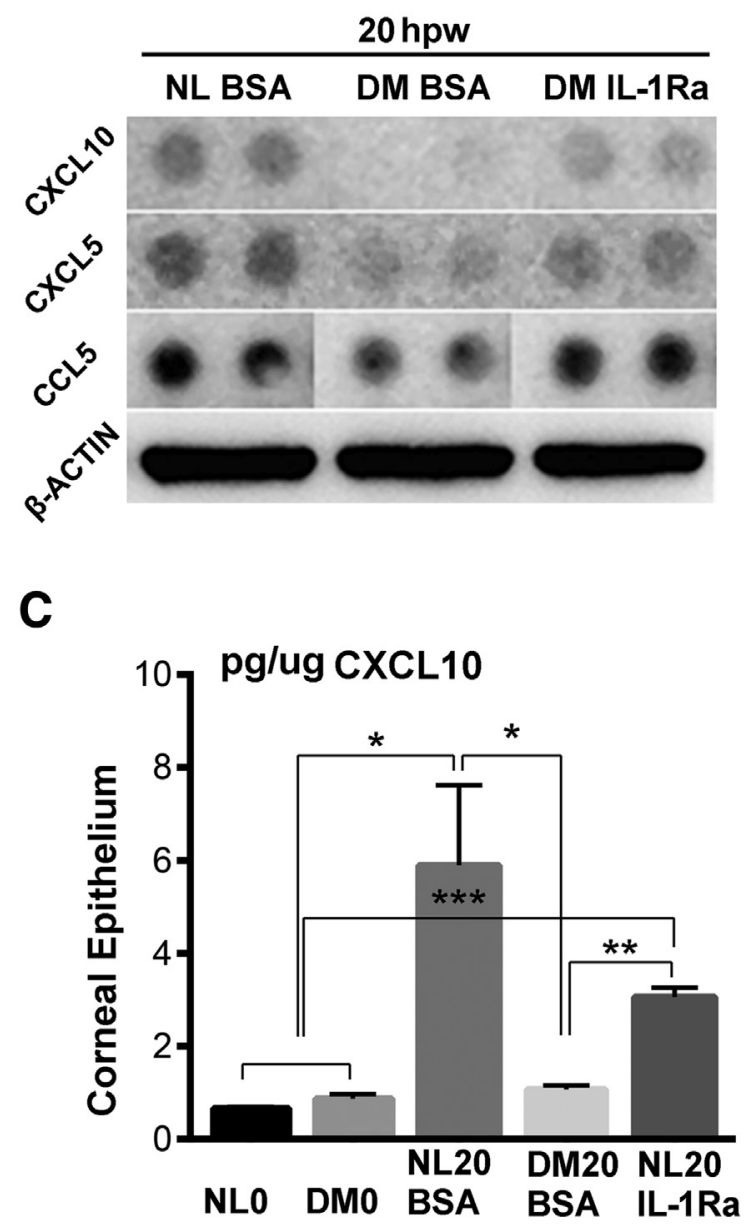

$\mathbf{B}$

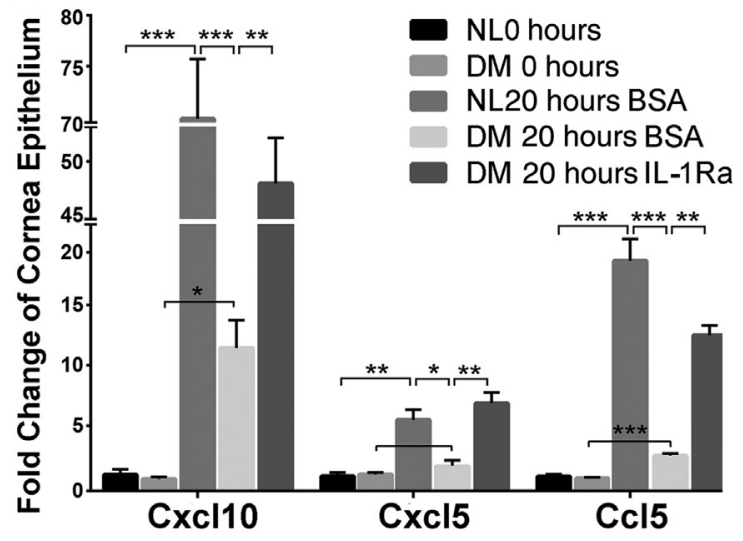

D

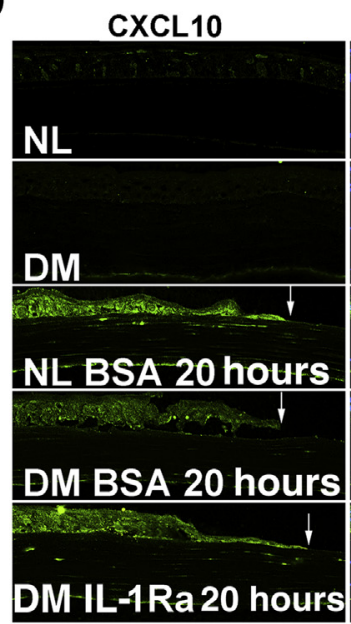

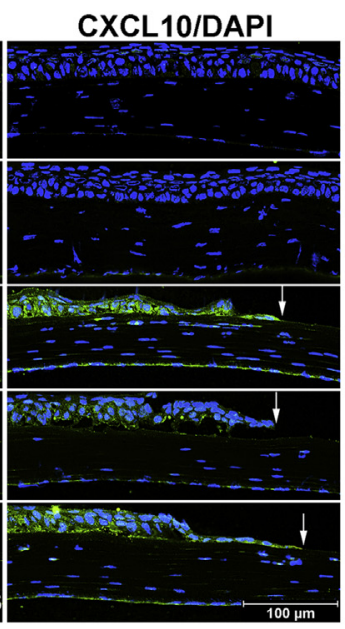

Figure 7 Exogenous IL-1 receptor antagonist (IL-1Ra) partially rescues suppressed expression of CXCL10, CXCL5, and chemokine ligand (CCL) 5 in healing diabetes mellitus (DM) corneas. A: Protein array analysis reveals the effect of exogenous IL-1Ra on cytokine/chemokine expression. Selected images for CXCL10, CXCL5, and CCL5 with Western blot analysis of actin as the loading control are shown. B: Real-time quantitative PCR analysis of CXCl10, CXCl5, and CcL5 in CECs. C: Enzyme-linked immunosorbent assay of CXCL10 in corneal epithelial cells. D: Immunofluorescence staining of CXCL10 in corneal frozen sections $(6 \mu \mathrm{m}$ thick). Arrows indicate epithelial leading edge. Two independent experiments were performed. Data are given as means \pm SEM (B and C). $n=3$ (B and $\mathbf{C}) .{ }^{*} P<0.05,{ }^{* *} P<0.01$, and ${ }^{* *} P<0.001$ (one-way analysis of variance). BSA, bovine serum albumin; NL, normal.

CECs, CXCL10 was greatly induced by wounding; this elevation was totally suppressed in the DM corneas, and restored partially by IL-1Ra treatment. At the tissue levels, CXCL10 staining was intensive at the leading edge of healing epithelium of the NL cornea; its intensity was much less in the DM cornea and restored somewhat by supplying IL-1Ra to the DM corneas (Figure 7D). To test the role of CXCL10 in mediating epithelium-wound healing, we applied 250 ng CXCL10 per cornea (Figure 8A). Although exogenous CXCL10 delayed wound closure in NL corneas, its presence significantly accelerated wound closure in the DM corneas (Figure 8B).

\section{Discussion}

In this study, we systematically analyzed the expression and the role of IL-1 $\beta$ and IL-1Ra in corneal wound healing in
NL and DM mice. We showed that wounding induced a marked up-regulation of IL-1Ra and IL-1 $\beta$ in the healing epithelia. More important, for the first time, we showed that diabetes greatly suppressed the wound-induced expression of IL-1Ra, but not epithelium-expressed IL-1 $\beta$, resulting in an increase in the ratio of IL-1 $1 \beta / \mathrm{sIL}-1 \mathrm{Ra}$ in healing CECs. Surprisingly, at the tissue levels, more IL- $1 \beta$ promoter activity was observed in NL than that in DM corneas during and after wound closure. Blockade of IL- $1 \beta$ or IL-1Ra in NL corneas resulted in delayed wound healing. Moreover, exogenous IL-1Ra, functioning as sIL-1Ra, accelerated delayed wound closure, increased proliferation, restored suppressed Akt phosphorylation/activation, and decreased apoptosis in healing DM corneas. IL-1Ra also increased neutrophils and NK cell infiltration, accelerated delayed sensory nerve regeneration, and restored to the certain extent the diabetes-suppressed expression of CXCL10. Functionally, the same dosage of CXCL10 attenuated in the 

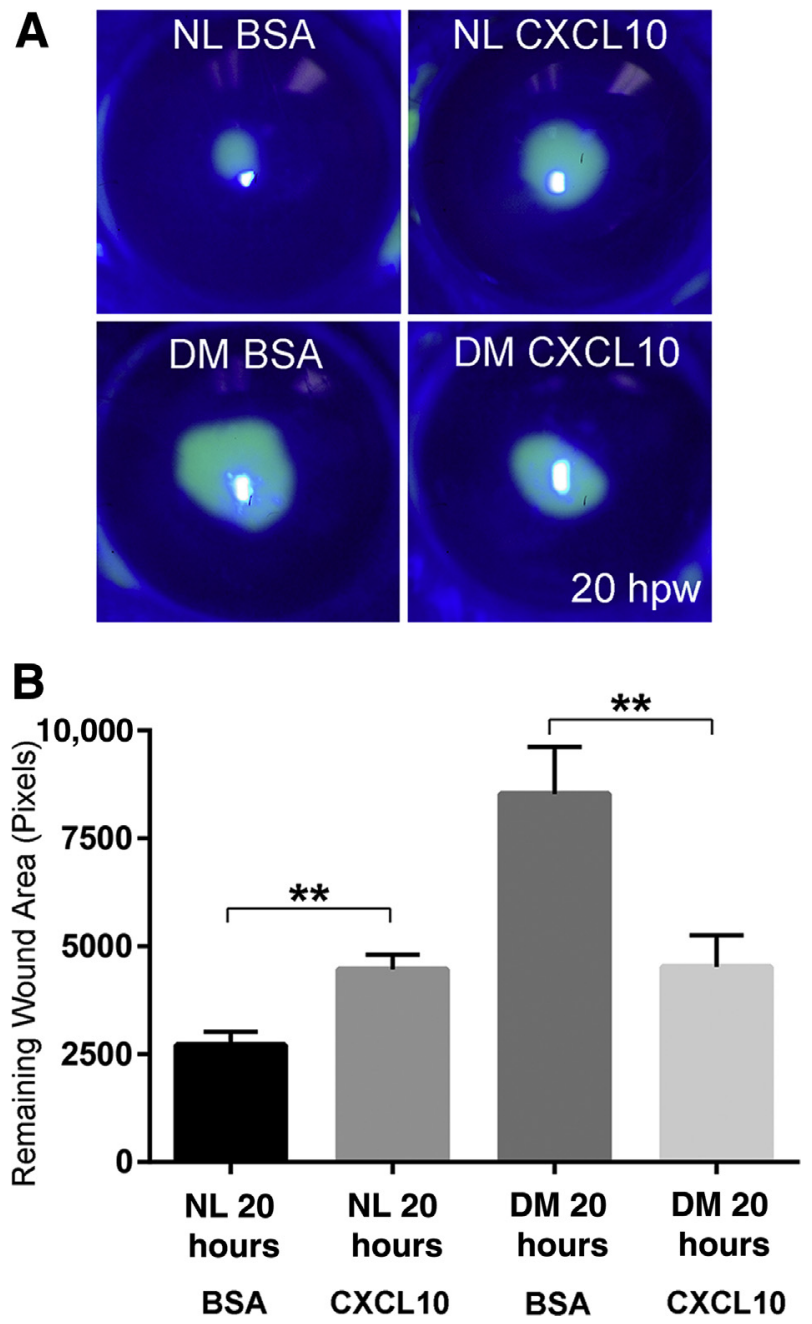

Figure 8 Role of CXCL10 in mediating epithelial wound healing. A: Normal (NL) mice were injected subconjunctivally with $5 \mu \mathrm{L}$ phosphatebuffered saline (PBS) containing $0.1 \%$ bovine serum albumin (BSA), left eyes, and $C X C 10$ recombinant protein $(50 \mathrm{ng} / \mu \mathrm{L})$, right eyes, and diabetes mellitus (DM) mice were subconjunctivally injected with $5 \mu \mathrm{L}$ PBS containing $0.1 \%$ BSA, left eyes, and CXCL10 recombinant protein $(50 \mathrm{ng} / \mu \mathrm{L})$, right eyes, 4 hours before epithelium debridement. Wounds were fluorescence stained, and imaged at 20 hours after wounding (hpw). B: The remaining wound areas were measured and presented. Two independent experiments were performed. Data are given as means \pm SEM (B). $n=5$ (B). ${ }^{* *} P<0.01$ (paired $t$-test).

$\mathrm{NL}$ and yet enhanced wound closure in DM corneas. Taken together, disturbed IL-1R signaling in DM CECs had adverse effects at multiple levels, including the suppression of proinflammatory cytokine/chemokine expression and immune cell infiltration, resulting in a decrease in overall early inflammatory response to wounding in the DM mouse corneas (Figure 9).

Because of their profound effects on inflammatory/immune responses, the expression and activation of the IL-1 subfamily members are under stringent regulation. ${ }^{33}$ Our study revealed several interesting observations regarding the expression of IL-1 $\beta$ and IL-1Ra: i) Because a low level of the IL-1Ra variant 2 mRNA was detected in the naive corneas, IL-1Ra molecules present in unwounded CECs or corneas are likely to be icIL1 Ra1, consistent with the fact that this isoform is constitutively expressed in epithelial cells. ${ }^{34}$ icIL-1Ra may not act to alter IL-1R mediated signaling, ${ }^{35}$ but target intracellular, pro-IL-1 $\alpha^{36-38}$ (Figure 9). ii) Wounding induced a robust expression of IL-1Ra-V2, but only moderate up-regulation of IL-1Ra-V1, suggesting that a large portion of the elevated levels of IL-1Ra detected by ELISA is transcribed from IL-1Ra-V2 to generate sIL-1Ra. Because the products of IL-1Ra-V1 are intracellular proteins, the increase of sIL-1Ra in the extracellular milieu of healing corneas should be substantial and sufficient to balance the elevated expression of IL-1 $\beta$. iii) The dramatic decrease in the amount of IL-1Ra-V2 transcripts, compared with that of IL-1Ra-V1 and IL- $1 \beta$, was observed in diabetic healing CECs. The decrease of IL-1Ra to a level similar to unwounded corneas suggests a great reduction of sIL-1Ra in diabetic healing epithelia, thus resulting in a great increase in the ratio of IL-1 $\beta / \mathrm{sIL}-1 \mathrm{Ra}$ in healing epithelial sheet. The balanced production of IL- $1 \beta$ and its natural, specific inhibitor, sIL-1Ra, plays an important role in tissue homeostasis and in the susceptibility to and severity of many human diseases. ${ }^{39,40}$ Wounding can initially induce IL- $1 \beta$ expression by endogenous danger signals or alarmins released from injured cells that can stimulate Toll-like receptors to induce IL- $1 \beta$ synthesis, ${ }^{41,42}$ as well as epidermal growth factor receptor activation. ${ }^{43} \mathrm{IL}-1 \beta$, in turn, induces specifically the expressions of IL-1 $\beta$ and sIL-1Ra, as shown in cultured human endometrial stromal cells. ${ }^{44}$ In diabetic tissues, such as the cornea, impairment of PI3K and ATK signaling, because of impaired epidermal growth factor receptor signaling, ${ }^{25}$ may differentially affect sIL-1Ra production, as shown in human monocytes ${ }^{45}$ resulting in an imbalance of IL- $1 \beta$ and sIL-1Ra, leading to delayed epithelial wound healing (Figure 9).

At the tissue level, the levels of IL- $1 \beta$, recognized as the gatekeeper of inflammation, ${ }^{46}$ were much lower in DM than that in NL corneas during wound healing. This extra amount of IL-1 $\beta$ molecules in normal wounded corneas or the lack of them in diabetic healing corneas may be related to the great number of IL-1 $\beta$-driven green fluorescent proteinpositive cells in normal, but not diabetic, corneas at $18 \mathrm{hpw}$ (Supplemental Figure S1).

Although most studies focused on the proinflammatory and autoimmune aspects of IL- $1 \beta,{ }^{47,48}$ our study revealed that IL-1 $\beta$ activity is required for proper wound healing because IL-1 $\beta$ neutralization antibodies attenuated wound healing in NL corneas. This observation is contradictory with reports in the literature that IL-1 $\beta$ neutralization usually improves tissue repair. ${ }^{49-51}$ Paradoxically, downregulation of IL-1Ra by siRNA also slowed epitheliumwound healing in the NL corneas. We propose a novel concept that the dynamic interactions of IL- $1 \beta$ and sIL-1Ra with IL-1R is critical for epithelium-wound healing.

Another novel observation is that when IL- $1 \beta$ activity was neutralized, the expression of IL-1Ra, but not IL-1 $\beta$, was attenuated in the NL corneas. On the other hand, the down-regulation of sIL-1Ra resulted in the suppression of 


\section{A Injured Epithelium of the Normal Cornea}

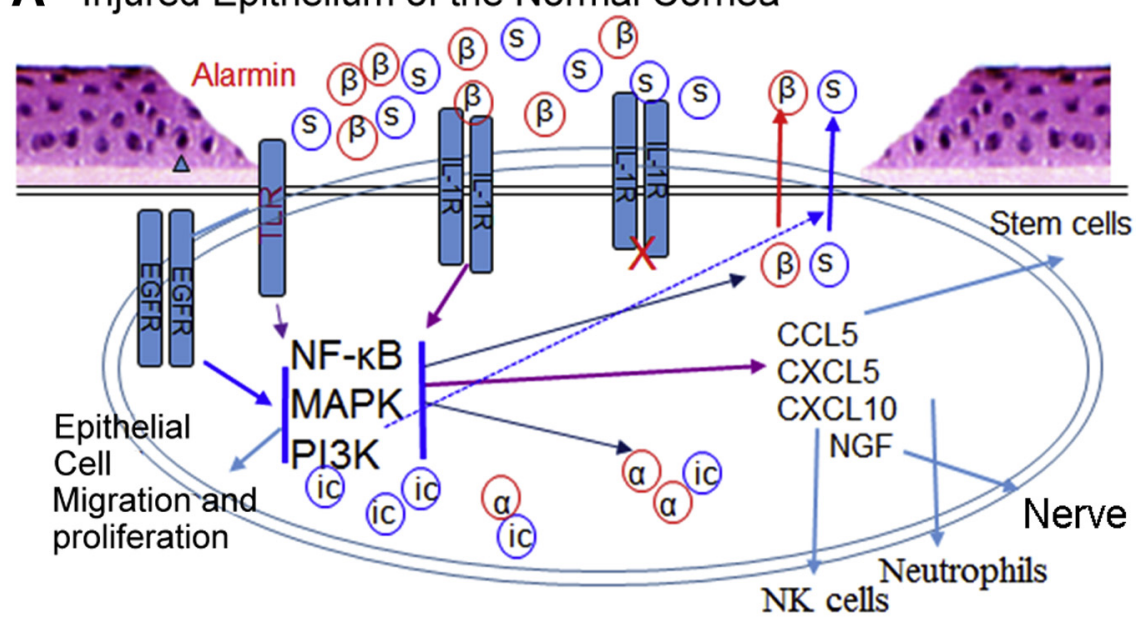

B Injured Epithelium of the Diabetic Cornea

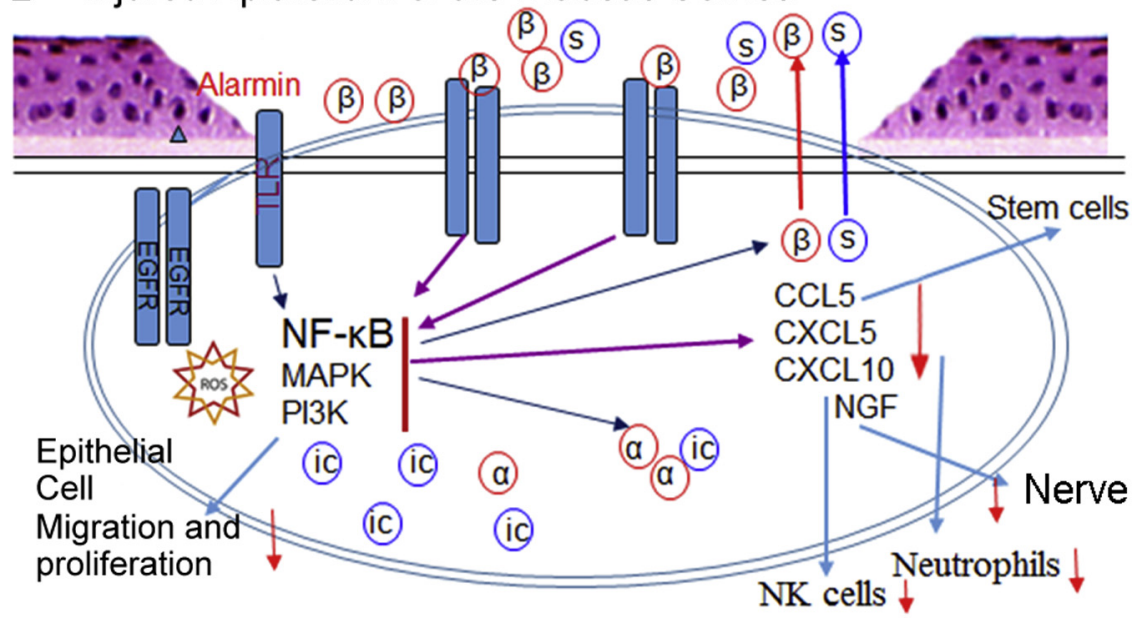

Figure 9 Schematic diagram deciphering the role of balanced IL-1 $\beta-$ IL-1 receptor antagonist (IL-1Ra) signaling in mediating epithelial wound healing and its defects in the diabetic corneas. A: In the normal corneas, epithelium injury causes the release of alarmins (eg, high mobility group box 1 protein), which activates Toll-like receptors (TLRs), resulting in the initial induction of IL- $1 \beta$ and the secreted form of IL-1Ra (sIL-1Ra). Both IL- $1 \beta$ and sIL-1Ra bind IL-1R and activate NF- $K B$, resulting in further induction of IL-1 $\beta$ and IL-1Ra in a balanced manner. IL-1 $\beta$ and IL-1Ra, in collaboration with tyrosine kinase receptors, such as epidermal growth factor receptor (EGFR), also participate in the activation of mitogen-activated protein kinase (MAPK) and phosphatidylinositol 3kinase (PI3K) pathways, resulting in the activation of epithelial proliferation and migration, and the expressions of chemokine ligand (CCL) 5 to active stem cells, CXCL5 to recruit neutrophils, CXCL10 to recruit and activate natural killer (NK) cells, and nerve growth factor to initiate sensory nerve regeneration. B: In the diabetic corneas, the activation of TLRs by alarmins, the presence of reactive oxygen species, and/or the impairment of EGFR signaling results in the down-regulation of MAPK and/or PI3K, leading to a marked reduction of IL-1Ra, whereas the expression of IL-1 $\beta$ is not affected. This causes a robust activation of NF- $\kappa B$, central regulator in ocular surface inflammation and diseases, without balanced action of MAPK and PI3K, leading to the down-regulation (red arrows) of chemokines and reduced infiltration of immune cells, and to the cell apoptosis and delayed wound healing and sensory nerve regeneration. Exogenous IL-1Ra ameliorates delayed epithelial wound healing in diabetic cornea by restoring balanced activation of IL-1R signaling. $\alpha$, IL-1 $\alpha ; \beta$, IL-1 $\beta$; ic, intracellular; s, soluble.
IL-1 $\beta$ expression at the mRNA levels. Thus, in the NL corneas, there is an interdependent relation between IL-1 $\beta$ and sIL-1Ra in terms of wound-evoked expressions, giving a balanced ratio of IL-1R agonist and antagonist required for proper response to environmental challenges.

Our data underline the role of increasing cell apoptosis and suppressing cell proliferation as underlying mechanisms for delayed epithelium-wound healing in the DM corneas. Diabetes is known to cause tissue damage by inducing apoptosis, such as that seen in endothelial cells in DM foot ulcer in rats with an elevated expression of IL-1 $\beta$ observed. ${ }^{52}$ However, a causative relation of elevated IL-1 $\beta$ and endothelial cell apoptosis was not established in the study. Our study provided direct in vivo evidence that exogenous IL-1Ra reduced the number of apoptotic cells in the healing epithelial sheet and in the stroma near the leading edge of healing DM corneas. On the other hand, proliferative cells were found away from the leading edge of migratory epithelia and in the limbal region in the $\mathrm{NL}$ corneas. Cell proliferations at different sites may provide different cell populations for stratification and progenitor cells. Fewer proliferative cells were found at the peripheral region near the limbus in the DM, compared with NL, corneas. The defects in cell proliferation and elevated cell apoptosis may be related to the decreased PI3K-Akt activities in the DM corneas during epithelial wound healing. Interestingly, the presence of IL-1Ra restored the levels of phospho-Akt at early time points ( 1 and $2 \mathrm{hpw}$ ). IL-1 $\beta$ has been shown to significantly reduce the expression of phosphoinositide 3-kinase p85 $\alpha$ and the phosphorylation of Akt, in adipocytes ${ }^{53}$; hence, Il-1Ra may promote PI3K-Akt activation through suppression of IL-1 $\beta$ activity. Moreover, the lack of sustained activation of PI3K-Akt may contribute to the fact that the presence of IL-1Ra can only partially reverse some adverse effects of diabetes on the cornea wound healing.

Our study also revealed that the numbers of two major infiltrative innate immune cells, neutrophils and NK cells, were reduced during epithelium wound closure in the DM mouse cornea, as that shown during cutaneous wound healing in DM rats. ${ }^{54}$ Neutrophils have been shown to act as an early response immune cells that play a key role in the healing of an epithelium-debridement wound. ${ }^{31}$ A large number of NK cells infiltrate into the cornea and participate in the modulation of 
epithelium-wound healing. ${ }^{32}$ It is not clear to date whether the decrease in the infiltration is because of the defects in these immune cells or the lack of cytokines/chemokines from the tissue to recruit these effector cells. The fact that the presence of IL-1Ra almost completely restored neutrophil infiltration and partially restored for NK cell infiltration in healing DM corneas suggest that IL-1R signaling within the cornea is involved in recruiting, maintaining, and/or activating these cells, leading to the acceleration of epithelium-wound closure. IL-1Ra may influence neutrophil and NK cell infiltrations by mediating the expressions of CCL5 and CXCL10 detected by cytokine protein array and confirmed by qPCR and/or ELISA assays (Figure 7).

We previously showed reduced innervation and reinnervation after epithelium wounding in Goto-Kakizaki type 2 DM rats. ${ }^{26}$ In the literature, IL-1Ra was shown to either play a protective role against transthyretin-mediated axonal loss in a mouse model of familial amyloidotic polyneuropathy ${ }^{55}$ or impair taste responses in the intact chorda tympani after nearby injury. ${ }^{56}$ Our results indicate a supportive role of IL-1Ra in the DM cornea and corroborate the potential use of IL-1Ra in promoting sensory nerve regeneration in DM peripheral tissues.

Our study using cytokine protein array revealed the potential involvement of CXCL5, CCL5, and CXCL10. The expression of these wound-responding genes was suppressed by diabetes; however, local treatment of anakinra reversed partially, but significantly, the diabetes-suppressed expression, suggesting the expression of these genes is under the control of IL-1 signaling. Although it was suspected to drive obesity, insulin resistance, and diabetes-derived pathologies, ${ }^{57}$ CXCL5 was shown to be a chemoattractant recruiting neutrophils into wounds and, therefore, facilitating healing of excisional skin wounds in mice.$^{58}$ CCL5 has been linked to DM nephropathy ${ }^{59}$ and DM cardiovascular autonomic complications. ${ }^{60}$ However, during the excisional skin wound repair process, CCL5, through CCR5, promotes bone marrow-derived progenitor cells homing to wound sites, hence accelerating wound healing in mice. ${ }^{61}$ The suppressed expression of CXCL5 and CCL5 may contribute to the defects in polymorphonuclear neutrophil infiltration and/or progenitor cell generation observed in DM wounded corneas.

Herein, we focused on CXCL10 and showed that it is greatly up-regulated in response to wound, and this upregulation was significantly suppressed in the DM corneas. Presence of IL-1Ra partially restored its expression at both mRNA and protein levels. Immunohistochemistry analysis revealed that CXCL10 primarily expressed at the leading edge of the migratory epithelium in the NL but not DM corneas with apparent elevation on IL-1Ra treatment in the DM corneas. Functionally, CXCL10 accelerates wound healing in the DM corneas, whereas, surprisingly, slowed wound closure in the NL corneas, suggesting a strict concentration-dependent role of CXCL10 for promoting wound response in the cornea. Thus, although Cxcl10 is considered an interferon-stimulated gene, ${ }^{62,63}$ our data indicate that its wound-induced expression is regulated by IL-1R signaling. Thus, we conclude that IL-1R, controlled by the IL-1 $\beta / \mathrm{IL}-1 \mathrm{Ra}$ ratio, serves as a converging point in mediating wound response and the overall decrease in IL-1R signaling contributing to the defects in wound healing in the diabetic corneas.

Our study clearly demonstrates a role of IL-1Ra in mediating corneal inflammation, epithelium wound closure, and sensory nerve regeneration through control of IL-1R signaling. We conclude that the ratio of IL- $1 \beta /$ sIL- 1 Ra is mostly responsible for these functions, and functional defects as found in diabetic corneas are related to suppressed expression of sIL-1RA. The current study could not rule out the contribution of icIL-1Ra to the regulation of corneal epithelial wound healing and to the pathogenesis of diabetic keratopathy, because wounding was shown to enhance IL-1Ra-V1 expression, which is also sensitive to diabetes suppression, albeit much milder than that of IL-1Ra-V2. The ELISA assay we used in this study was unable to distinguish between these isoforms or their cellular localization. The fact that exogenous IL-1Ra accelerates diabetic wound healing and restores defective diabetic signaling supports a major role of sIL-1Ra. Further study to define the role of icIL-1Ra, potentially targeting IL- $1 \alpha$, is warranted.

Finally, s.c. injection of anakinra has been used clinically to treat rheumatoid arthritis for $>15$ years with injection site discomfort and occasional infection, but not the systematic infection because of the suppressed IL- $1 \beta$ activity, as major adverse effects. ${ }^{16}$ In a prospective phase 1 and 2 clinical trial for treating dry eye disease, topical anakinra $2.5 \%$ and $5 \%$, three times daily for 12 weeks, was well tolerated compared with vehicle, with no reports of serious adverse reactions attributable to the therapy. ${ }^{64}$ Our study points to its topical application to treat DM ulceration and delayed wound healing in human corneas and potentially in the skin. Indeed, preliminary study performed by a contract preclinical testing company showed promising result in promoting skin wound healing of topical Anakinra in Pluronic F127 gel in Zucker type $2 \mathrm{DM}$ rats. This can be readily translated into the clinical use to treat DM patients with persistent, unhealable wounds in cornea and the skin.

\section{Acknowledgments}

C.Y. acquired, analyzed, and interpreted data, and edited the manuscript. N.G. and H.S. performed laboratory testing and drafted methods. J.Y., P.L., and L.Z. analyzed and interpreted data and wrote the discussion. X.F. designed the study, interpreted the data, and edited the manuscript. F.-S.Y. designed the study and recruited, collected samples, analyzed data, and wrote, edited, and approved the manuscript. F.-S.Y. is the guarantor of this work and had full access to all of the data in the study and takes responsibility for the integrity of the data and the accuracy of the data analysis. All authors approved this submission. 


\section{Supplemental Data}

Supplemental material for this article can be found at http://dx.doi.org/10.1016/j.ajpath.2016.01.019.

\section{References}

1. Kaji Y: Prevention of diabetic keratopathy. Br J Ophthalmol 2005, 89:254-255

2. Pflugfelder SC: Is autologous serum a tonic for the ailing corneal epithelium? Am J Ophthalmol 2006, 142:316-317

3. Bikbova G, Oshitari T, Tawada A, Yamamoto S: Corneal changes in diabetes mellitus. Curr Diabetes Rev 2012, 8:294-302

4. Chikama T, Wakuta M, Liu Y, Nishida T: Deviated mechanism of wound healing in diabetic corneas. Cornea 2007, 26:S75-S81

5. Esser N, Legrand-Poels S, Piette J, Scheen AJ, Paquot N: Inflammation as a link between obesity, metabolic syndrome and type 2 diabetes. Diabetes Res Clin Pract 2014, 105:141-150

6. Donath MY: Targeting inflammation in the treatment of type 2 diabetes. Diabetes Obes Metab 2013, 15(Suppl 3):193-196

7. Garcia C, Feve B, Ferre P, Halimi S, Baizri H, Bordier L, Guiu G, Dupuy O, Bauduceau B, Mayaudon H: Diabetes and inflammation: fundamental aspects and clinical implications. Diabetes Metab 2010, $36: 327-338$

8. Schmidt MI, Duncan BB, Sharrett AR, Lindberg G, Savage PJ, Offenbacher S, Azambuja MI, Tracy RP, Heiss G: Markers of inflammation and prediction of diabetes mellitus in adults (Atherosclerosis Risk in Communities study): a cohort study. Lancet 1999, 353:1649-1652

9. Schwartzman ML, Iserovich P, Gotlinger K, Bellner L, Dunn MW, Sartore M, Grazia Pertile M, Leonardi A, Sathe S, Beaton A, Trieu L, Sack R: Profile of lipid and protein autacoids in diabetic vitreous correlates with the progression of diabetic retinopathy. Diabetes 2010, 59:1780-1788

10. Donath MY, Dalmas E, Sauter NS, Boni-Schnetzler M: Inflammation in obesity and diabetes: islet dysfunction and therapeutic opportunity. Cell Metab 2013, 17:860-872

11. Helqvist $\mathrm{S}$ : Interleukin 1 beta-mediated destruction of pancreatic betacells in vitro: a model of beta-cell destruction in insulin-dependent diabetes mellitus? Dan Med Bull 1994, 41:151-166

12. Mandrup-Poulsen T, Zumsteg U, Reimers J, Pociot F, Morch L, Helqvist S, Dinarello CA, Nerup J: Involvement of interleukin 1 and interleukin 1 antagonist in pancreatic beta-cell destruction in insulindependent diabetes mellitus. Cytokine 1993, 5:185-191

13. Banerjee M, Saxena M: Interleukin-1 (IL-1) family of cytokines: role in type 2 diabetes. Clin Chim Acta 2012, 413:1163-1170

14. Amin A, Choi SK, Galan M, Kassan M, Partyka M, Kadowitz P, Henrion D, Trebak M, Belmadani S, Matrougui K: Chronic inhibition of endoplasmic reticulum stress and inflammation prevents ischaemia-induced vascular pathology in type II diabetic mice. J Pathol 2012, 227:165-174

15. Weber A, Wasiliew P, Kracht M: Interleukin-1 (IL-1) pathway. Sci Signal 2010, 3:cm1

16. Cavalli G, Dinarello CA: Treating rheumatological diseases and co-morbidities with interleukin-1 blocking therapies. Rheumatology (Oxford) 2015, 54:2134-2144

17. Wilson SE, Mohan RR, Mohan RR, Ambrosio R Jr, Hong J, Lee J: The corneal wound healing response: cytokine-mediated interaction of the epithelium, stroma, and inflammatory cells. Prog Retin Eye Res 2001, 20:625-637

18. Hong JW, Liu JJ, Lee JS, Mohan RR, Mohan RR, Woods DJ, He YG, Wilson SE: Proinflammatory chemokine induction in keratocytes and inflammatory cell infiltration into the cornea. Invest Ophthalmol Vis Sci 2001, 42:2795-2803

19. Stapleton WM, Chaurasia SS, Medeiros FW, Mohan RR, Sinha S, Wilson SE: Topical interleukin-1 receptor antagonist inhibits inflammatory cell infiltration into the cornea. Exp Eye Res 2008, 86: 753-757

20. Ishida Y, Kondo T, Kimura A, Matsushima K, Mukaida N: Absence of IL-1 receptor antagonist impaired wound healing along with aberrant NF-kappaB activation and a reciprocal suppression of TGF-beta signal pathway. J Immunol 2006, 176:5598-5606

21. Thomay AA, Daley JM, Sabo E, Worth PJ, Shelton LJ, Harty MW, Reichner JS, Albina JE: Disruption of interleukin-1 signaling improves the quality of wound healing. Am J Pathol 2009, 174:2129-2136

22. Ljubimov AV, Saghizadeh M: Progress in corneal wound healing. Prog Retin Eye Res 2015, 49:17-45

23. Bettahi I, Sun H, Gao N, Wang F, Mi X, Chen W, Liu Z, Yu FS: Genome-wide transcriptional analysis of differentially expressed genes in diabetic, healing corneal epithelial cells: hyperglycemiasuppressed TGFbeta3 expression contributes to the delay of epithelial wound healing in diabetic corneas. Diabetes 2014, 63:715-727

24. Sun H, Mi X, Gao N, Yan C, Yu FS: Hyperglycemia-suppressed expression of serpine 1 contributes to delayed epithelial wound healing in diabetic mouse corneas. Invest Ophthalmol Vis Sci 2015, 56: 3383-3392

25. Xu K, Yu FS: Impaired epithelial wound healing and EGFR signaling pathways in the corneas of diabetic rats. Invest Ophthalmol Vis Sci 2011, 52:3301-3308

26. Wang F, Gao N, Yin J, Yu FS: Reduced innervation and delayed re-innervation after epithelial wounding in type 2 diabetic GotoKakizaki rats. Am J Pathol 2012, 181:2058-2066

27. Yin J, Huang J, Chen C, Gao N, Wang F, Yu FS: Corneal complications in streptozocin-induced type I diabetic rats. Invest Ophthalmol Vis Sci 2011, 52:6589-6596

28. Hedberg-Buenz A, Christopher MA, Lewis CJ, Meyer KJ, Rudd DS, Dutca LM, Wang K, Garvin MK, Scheetz TE, Abramoff MD, Harper MM, Anderson MG: RetFM-J, an ImageJ-based module for automated counting and quantifying features of nuclei in retinal whole-mounts. Exp Eye Res 2015, [Epub ahead of print] doi:10.1016/ j.exer.2015.07.020

29. Arend WP, Malyak M, Guthridge CJ, Gabay C: Interleukin-1 receptor antagonist: role in biology. Annu Rev Immunol 1998, 16:27-55

30. Gao N, Yu FX: Chitinase 3-like-1 promotes Candida albicans killing and preserves corneal structure and function by controlling host antifungal responses. Infect Immun 2015, 83:4154-4164

31. Gagen D, Laubinger S, Li Z, Petrescu MS, Brown ES, Smith CW, Burns AR: ICAM-1 mediates surface contact between neutrophils and keratocytes following corneal epithelial abrasion in the mouse. Exp Eye Res 2010, 91:676-684

32. Liu Q, Smith CW, Zhang W, Burns AR, Li Z: NK cells modulate the inflammatory response to corneal epithelial abrasion and thereby support wound healing. Am J Pathol 2012, 181:452-462

33. Garlanda C, Dinarello CA, Mantovani A: The interleukin-1 family: back to the future. Immunity $2013,39: 1003-1018$

34. Gabay C, Smith MF Jr, Arend WP: The human intracellular interleukin 1 receptor antagonist promoter appropriately regulates gene expression in keratinocytes and gastrointestinal epithelial cells in vivo. Cytokine 1999, 11:561-570

35. Evans I, Dower SK, Francis SE, Crossman DC, Wilson HL: Action of intracellular IL-1Ra (Type 1) is independent of the IL-1 intracellular signalling pathway. Cytokine 2006, 33:274-280

36. Banda NK, Guthridge C, Sheppard D, Cairns KS, Muggli M, Bech-Otschir D, Dubiel W, Arend WP: Intracellular IL-1 receptor antagonist type 1 inhibits IL-1-induced cytokine production in keratinocytes through binding to the third component of the COP9 signalosome. J Immunol 2005, 174:3608-3616

37. Merhi-Soussi F, Berti M, Wehrle-Haller B, Gabay C: Intracellular interleukin-1 receptor antagonist type 1 antagonizes the stimulatory effect of interleukin-1 alpha precursor on cell motility. Cytokine 2005, 32:163-170

38. Palmer G, Talabot-Ayer D, Kaya G, Gabay C: Type I IL-1 receptor mediates IL-1 and intracellular IL-1 receptor antagonist effects in skin 
inflammation. J Invest Dermatol 2007, 127:1938-1946

39. Molnarfi N, Gruaz L, Dayer JM, Burger D: Opposite regulation of IL-1beta and secreted IL-1 receptor antagonist production by phosphatidylinositide-3 kinases in human monocytes activated by lipopolysaccharides or contact with T cells. J Immunol 2007, 178: 446-454

40. Arend WP: The balance between IL-1 and IL-1Ra in disease. Cytokine Growth Factor Rev 2002, 13:323-340

41. Doz E, Noulin N, Boichot E, Guenon I, Fick L, Le Bert M, Lagente V, Ryffel B, Schnyder B, Quesniaux VF, Couillin I: Cigarette smokeinduced pulmonary inflammation is TLR4/MyD88 and IL1R1/MyD88 signaling dependent. J Immunol 2008, 180:1169-1178

42. Sims JE, Smith DE: The IL-1 family: regulators of immunity. Nat Rev Immunol 2010, 10:89-102

43. Xu KP, Ding Y, Ling J, Dong Z, Yu FS: Wound-induced HB-EGF ectodomain shedding and EGFR activation in corneal epithelial cells. Invest Ophthalmol Vis Sci 2004, 45:813-820

44. Huang HY, Wen Y, Kruessel JS, Raga F, Soong YK, Polan ML: Interleukin (IL)-1beta regulation of $\mathrm{IL}-1$ beta and $\mathrm{IL}-1$ receptor antagonist expression in cultured human endometrial stromal cells. J Clin Endocrinol Metab 2001, 86:1387-1393

45. Carpintero R, Brandt KJ, Gruaz L, Molnarfi N, Lalive PH, Burger D: Glatiramer acetate triggers PI3Kdelta/Akt and MEK/ERK pathways to induce IL-1 receptor antagonist in human monocytes. Proc Natl Acad Sci U S A 2010, 107:17692-17697

46. Dinarello CA: A clinical perspective of IL-1beta as the gatekeeper of inflammation. Eur J Immunol 2011, 41:1203-1217

47. Goldbach-Mansky R: Immunology in clinic review series: focus on autoinflammatory diseases: update on monogenic autoinflammatory diseases: the role of interleukin (IL)-1 and an emerging role for cytokines beyond IL-1. Clin Exp Immunol 2012, 167:391-404

48. Dinarello CA, Donath MY, Mandrup-Poulsen T: Role of IL-1beta in type 2 diabetes. Curr Opin Endocrinol Diabetes Obes 2010, 17 : 314-321

49. Clausen F, Hanell A, Israelsson C, Hedin J, Ebendal T, Mir AK, Gram H, Marklund N: Neutralization of interleukin-1beta reduces cerebral edema and tissue loss and improves late cognitive outcome following traumatic brain injury in mice. Eur J Neurosci 2011, 34: $110-123$

50. Clausen F, Hanell A, Bjork M, Hillered L, Mir AK, Gram H, Marklund N: Neutralization of interleukin-1beta modifies the inflammatory response and improves histological and cognitive outcome following traumatic brain injury in mice. Eur J Neurosci 2009, 30:385-396

51. Hwang MW, Matsumori A, Furukawa Y, Ono K, Okada M, Iwasaki A, Hara M, Miyamoto T, Touma M, Sasayama S: Neutralization of interleukin-1beta in the acute phase of myocardial infarction promotes the progression of left ventricular remodeling. J Am Coll Cardiol 2001, 38:1546-1553
52. Kandhare AD, Ghosh P, Bodhankar SL: Naringin, a flavanone glycoside, promotes angiogenesis and inhibits endothelial apoptosis through modulation of inflammatory and growth factor expression in diabetic foot ulcer in rats. Chem Biol Interact 2014, 219:101-112

53. Gao D, Madi M, Ding C, Fok M, Steele T, Ford C, Hunter L, Bing C: Interleukin-1beta mediates macrophage-induced impairment of insulin signaling in human primary adipocytes. Am J Physiol Endocrinol Metab 2014, 307:E289-E304

54. Ebaid H, Salem A, Sayed A, Metwalli A: Whey protein enhances normal inflammatory responses during cutaneous wound healing in diabetic rats. Lipids Health Dis 2011, 10:235

55. Goncalves NP, Teixeira-Coelho M, Saraiva MJ: Protective role of anakinra against transthyretin-mediated axonal loss and cell death in a mouse model of familial amyloidotic polyneuropathy. J Neuropathol Exp Neurol 2015, 74:203-217

56. Shi L, He L, Sarvepalli P, McCluskey LP: Functional role for interleukin-1 in the injured peripheral taste system. J Neurosci Res 2012, 90:816-830

57. Chavey C, Fajas L: CXCL5 drives obesity to diabetes, and further. Aging (Albany NY) 2009, 1:674-677

58. Hasegawa M, Higashi K, Matsushita T, Hamaguchi Y, Saito K, Fujimoto M, Takehara K: Dermokine inhibits ELR $(+)$ CXC chemokine expression and delays early skin wound healing. J Dermatol Sci 2013, 70:34-41

59. Lin M, Yiu WH, Li RX, Wu HJ, Wong DW, Chan LY, Leung JC, Lai KN, Tang SC: The TLR4 antagonist CRX-526 protects against advanced diabetic nephropathy. Kidney Int 2013, 83:887-900

60. Li G, Xu H, Zhu S, Xu W, Qin S, Liu S, Tu G, Peng H, Qiu S, Yu S, Zhu Q, Fan B, Zheng C, Liang S: Effects of neferine on CCL5 and CCR5 expression in SCG of type 2 diabetic rats. Brain Res Bull 2013, 90:79-87

61. Ishida Y, Kimura A, Kuninaka Y, Inui M, Matsushima K, Mukaida N, Kondo T: Pivotal role of the CCL5/CCR5 interaction for recruitment of endothelial progenitor cells in mouse wound healing. J Clin Invest 2012, 122:711-721

62. Saha B, Jyothi Prasanna S, Chandrasekar B, Nandi D: Gene modulation and immunoregulatory roles of interferon gamma. Cytokine 2010, 50:1-14

63. Harikumar KB, Yester JW, Surace MJ, Oyeniran C, Price MM, Huang WC, Hait NC, Allegood JC, Yamada A, Kong X, Lazear HM, Bhardwaj R, Takabe K, Diamond MS, Luo C, Milstien S, Spiegel S, Kordula T: K63-linked polyubiquitination of transcription factor IRF1 is essential for IL-1-induced production of chemokines CXCL10 and CCL5. Nat Immunol 2014, 15:231-238

64. Amparo F, Dastjerdi MH, Okanobo A, Ferrari G, Smaga L, Hamrah P, Jurkunas U, Schaumberg DA, Dana R: Topical interleukin 1 receptor antagonist for treatment of dry eye disease: a randomized clinical trial. JAMA Ophthalmol 2013, 131:715-723 